\title{
The effectiveness of psychological support interventions for those exposed to mass infectious disease outbreaks: a systematic review
}

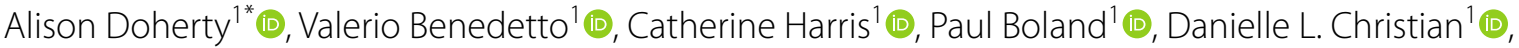 \\ James Hill ${ }^{1}$, Gita Bhutani ${ }^{2}$ and Andrew J. Clegg ${ }^{1}$ (i)
}

\begin{abstract}
Background: Mass outbreaks such as pandemics are associated with mental health problems requiring effective psychological interventions. Although several forms of psychological interventions may be advocated or used, some may lack strong evidence of efficacy and some may not have been evaluated in mass infectious disease outbreaks. This paper reports a systematic review of published studies (PROSPERO CRD:42020182094. Registered: 24.04.2020) examining the types and effectiveness of psychological support interventions for the general population and healthcare workers exposed to mass infectious disease outbreaks.
\end{abstract}

Methods: A systematic review was conducted. Randomised Controlled Trials (RCT) were identified through searches of electronic databases: Medline (Ovid), Embase (Ovid), PsycINFO (EBSCO) and the Cochrane Library Database from inception to 06.05.2021 using an agreed search strategy. Studies were included if they assessed the effectiveness of interventions providing psychological support to the general population and / or healthcare workers exposed to mass infectious disease outbreaks. Studies were excluded if they focused on man-made or natural disasters or if they included armed forces, police, fire-fighters or coastguards.

Results: Twenty-two RCTs were included after screening. Various psychological interventions have been used: therapist-guided therapy $(n=1)$; online counselling $(n=1)$; 'Emotional Freedom Techniques' $(n=1)$; mobile phone apps $(n=2)$; brief crisis intervention $(n=1)$; psychological-behavioural intervention $(n=1)$; Cognitive Behavioural Therapy $(n=3)$; progressive muscle relaxation $(n=2)$; emotional-based directed drawing $(n=1)$; psycho-educational debriefing $(n=1)$; guided imagery $(n=1)$; Eye Movement Desensitization and Reprocessing (EMDR) $(n=1)$; expressive writing $(n=2)$; tailored intervention for patients with a chronic medical conditions $(n=1)$; community health workers $(n=1)$; self-guided psychological intervention $(n=1)$, and a digital behaviour change intervention $(n=1)$. Meta-analyses showed that psychological interventions had a statistically significant benefit in managing depression (Standardised Mean Difference [SMD]: -0.40; 95\% Confidence Interval [Cl]: - 0.76 to - 0.03), and anxiety (SMD: -0.72;

\footnotetext{
*Correspondence: adoherty7@uclan.ac.uk

1 Synthesis, Economic Evaluations and Decision Science (SEEDS) Group,

Faculty of Health \& Care, University of Central Lancashire (UCLan),

Preston PR1 2HE, UK

Full list of author information is available at the end of the article
} original author(s) and the source, provide a link to the Creative Commons licence, and indicate if changes were made. The images or other third party material in this article are included in the article's Creative Commons licence, unless indicated otherwise in a credit line to the material. If material is not included in the article's Creative Commons licence and your intended use is not permitted by statutory regulation or exceeds the permitted use, you will need to obtain permission directly from the copyright holder. To view a copy of this licence, visit http://creativecommons.org/licenses/by/4.0/. The Creative Commons Public Domain Dedication waiver (http://creativeco mmons.org/publicdomain/zero/1.0/) applies to the data made available in this article, unless otherwise stated in a credit line to the data. 
95\% Cl: -1.03 to -0.40 ). The effect on stress was equivocal (SMD: $0.16 ; 95 \% \mathrm{Cl}:-0.19$ to 0.51 ). The heterogeneity of studies, studies' high risk of bias, and the lack of available evidence means uncertainty remains.

Conclusions: Further RCTs and intervention studies involving representative study populations are needed to inform the development of targeted and tailored psychological interventions for those exposed to mass infectious disease outbreaks.

Keywords: Review, Pandemics, Public health, Mental health, Interventions, Mass outbreaks

\section{Background}

Over a decade before the outbreak of the COVID-19 pandemic in 2020, healthcare organisations across the world were preparing for an influenza pandemic of unpredictable scale and impact [1-5], involving increased rates of morbidity and mortality among the general population, high healthcare demands, and considerable psychological stress amongst healthcare workers $[1,2,4]$. It is evident that the effects of the COVID-19 pandemic are pervasive affecting the mental health of many of those exposed [6, 7], including healthcare workers [8-11].

The effects on healthcare workers is a concern, given their importance in preventing and managing the consequences of pandemics $[12,13]$. A mass outbreak puts healthcare workers in unprecedented situations including dilemmas over how to balance their own physical and mental healthcare needs along with those of their patients [13]. Experience with the SARS outbreak in 2003 highlighted how the acute stress of an outbreak can impact on the mental health and wellbeing of healthcare workers and how this, in turn, can affect their ability to care for patients $[14,15]$. During the SARS outbreak many healthcare workers reduced their working hours and face-to-face involvement with patients $[14,15]$. Two years after the mass infectious disease outbreak, healthcare practitioners that had treated SARS patients had elevated signs of chronic stress compared to healthcare practitioners not treating SARS patients [15]. SARS$\mathrm{CoV}-2$ is a virus that can cause COVID-19, a mass infectious disease. Reducing the mental health impact of those exposed to such mass infectious disease outbreaks is fundamental to the continued provision of health and social care $[2,5]$. However, the planning and delivery of such psychological support may differ within and between countries [16-18].

Although several forms of psychological interventions [19] may be advocated or used, some are recognised as being harmful, others lack strong evidence of efficacy and some have not been evaluated in mass infectious disease outbreaks [16, 19-22]. Importantly, specific population groups such as children and young people, ethnic minorities, and people on low incomes, may be more vulnerable to mental health problems associated with mass infectious disease outbreaks and require targeted interventions [23-28]. Such uncertainties call for the development and implementation of effective targeted interventions for all those exposed to mass infectious disease outbreaks $[11,16,26]$. Despite several systematic reviews assessing interventions to manage psychological problems associated with different types of mass outbreaks [28-31], doubts remain due to certain shortcomings. Some focus on different types of disasters (not just epidemics or pandemics), on interventions for children only, for healthcare workers only, and/or exclude recent evidence [28-31]. Consequently, we conducted a systematic review to identify the types of psychological interventions used in previous mass infectious disease outbreaks (similar to COVID-19) and during the COVID-19 pandemic to support the general population and healthcare workers, and how effective these interventions have been. Findings are expected to provide evidence-based information to inform research, policy and practice.

\section{Methods}

\section{Search strategy}

Our systematic review was conducted according to a pre-registered protocol (PROSPERO 2020 CRD:42020182094. Registered: 24.04.2020), following established PRISMA guidance and reporting standards [32, 33]. We identified studies through searches of electronic databases, including Medline (Ovid), Embase (Ovid), PsycINFO (EBSCO) and the Cochrane Library Database, using a predetermined search strategy and prepiloted screening tool (Additional files $1 \&$ 2). Databases were searched from inception to 06.05.2021.

\section{Study selection \\ Inclusion}

We included Randomised Controlled Trials (RCTs) including Cluster RCTs and Parallel RCTs that assessed the comparative effectiveness of interventions providing psychological support to the general population (all ages) and/or healthcare workers (e.g. nurses, doctors) exposed to mass infectious disease outbreaks including COVID19, H1N1, swine flu, SARS, Ebola, and MERS. Psychological support could include interventions such as cognitive behavioural, psycho-social or psycho-educational interventions. Any comparator was included, for example: 


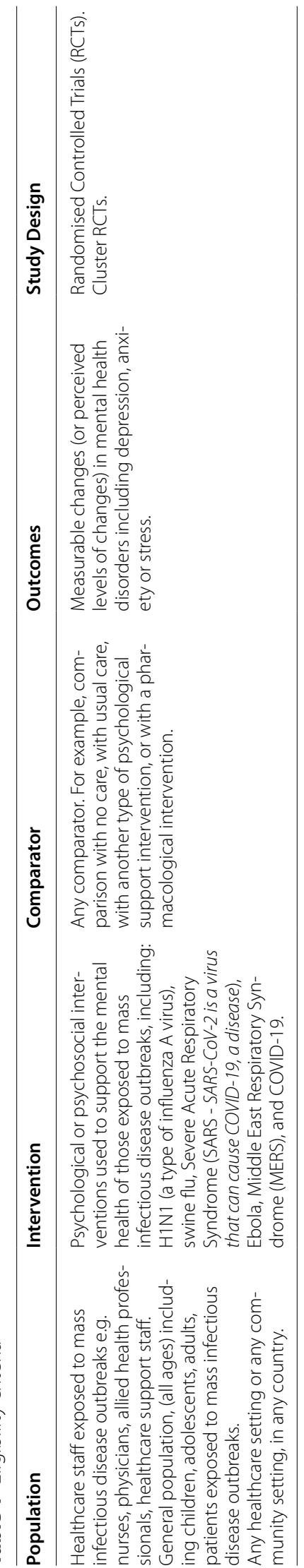


comparison with no intervention, with usual care, comparisons between a psychological intervention and another type of psychological intervention(s), or pharmacological intervention(s). Effectiveness was assessed using any measure of changes in psychological or mental health impact: specifically reduced depression, anxiety or stress levels measured by a recognised outcome measurement tool such as the Patient Health Questionnaire depression scale (PHQ-9) or the Generalized Anxiety Disorder scale (GAD-7) or the Depression, Anxiety and Stress Scale (DASS-21). Relevant systematic reviews were only used to identify any RCTs that may not have already been identified by the review's initial electronic searches.

\section{Exclusion}

Non-RCT studies were excluded. Studies were excluded if they involved armed forces, police, firefighters, coastguards; terrorism / war; or, man-made or natural disasters (e.g. tsunamis). Abstracts, editorials, commentaries, or opinion pieces were excluded, as were studies where the full text was not available or if they were not published in English. Table 1 summarises the eligibility criteria for the review. Titles and abstracts of papers from the searches were screened independently by pairs of reviewers $(\mathrm{AJD} / \mathrm{VB} / \mathrm{CH} / \mathrm{AJC})$, using an eligibility criteria screening tool (Additional file 2). Full-text manuscripts of studies that met the criteria at the title and abstract screening stage were retrieved and screened independently by the pairs of reviewers (AJD/VB/CH/AJC) using the same criteria.

\section{Data extraction and quality assessment}

The pairs of two reviewers (AJD/VB/CH/AJC) independently extracted each study's data using a pre-piloted data extraction form, checking each other's extraction. Data were extracted into the following categories: study (first author, year); country; setting; study aims; mass outbreak (type); participant characteristics; intervention(s); comparator(s); and outcomes. The pairs of reviewers independently assessed the quality of included studies using the Cochrane Risk of Bias (RoBv2) Tool [34] and checked one another's assessments. Any discrepancies at any stage were resolved through discussions to reach mutual consensus.

\section{Data analysis}

Studies were synthesised narratively with tabulation of results. Where studies presented continuous outcome measures of depression, anxiety and stress, they were pooled through meta-analysis presenting results as point estimates and $95 \%$ confidence intervals $(\mathrm{CI})$. Although outcomes were measured on different scales, they were based on the same underlying construct, allowing standardised weighted mean differences (SMDs) to be estimated. Given the variation in the studies, randomeffects models were used to pool outcomes. Heterogeneity was assessed through visual inspection of forest plots and the calculation of the $\mathrm{I}^{2}$ statistics. Pre-planned subgroup analyses explored the influence of study setting, participants and risk of bias. Meta-analyses were conducted using Review Manager version 5.4.1 (Cochrane Collaboration 2020).

\section{Results}

A combined total of 12,104 citations were identified from the database searches after removal of duplicates. No further eligible RCTs were identified from other sources (reference checks of relevant reviews). Twenty-two papers met the eligibility criteria and reported information for quality appraisal and data extraction [35-56]. Fig. 1 summarises the study selection process. Table 2 provides a summary of the included studies.

\section{Quality assessment}

Most of the included studies were assessed as being of high risk of bias $(n=12 / 22)$, or of 'some concern' $(n=8 / 22)$. Two studies were assessed as being of low risk of bias [54, 55]. Studies that were considered as high risk or of 'some concern' showed shortcomings due to either their randomisation process, deviations from their intended interventions, missing outcome data, their measurement of outcomes, or selective reporting. Table 3 provides an overall summary of the individual risk of bias assessments for each of the included studies.

\section{Year and location of studies}

Most of the studies included in the review were published in 2020 or $2021(n=21)$. One study was published in 2006 [46]. Studies were conducted in several different countries: Belgium $(n=1)$ [53], Canada $(n=1)$ [45], China $(n=6)$ [40-44, 56], Hong Kong $(n=1)$ [46], Iran $(n=3)[39,48,51]$, Italy $(n=3)[36,49,50]$, Oman $(n=1)$ [35], Serbia $(n=1)$ [54], Spain $(n=1)$ [38], Sweden $(n=1)$ [55], and Turkey $(n=2)$ [37, 47]. One study [52] involved participants from seven different countries (Australia, Canada, France, Mexico, Spain, UK and USA). Nine of these studies' countries were high-income countries (HICs) [35, 36, 38, 45, 46, 49, 50, 53, 55] and 12 were upper-middle-income countries (UMICs) [37, 39-44, $47,48,51,54,56]$. One study was conducted in countries from both HIC and UMIC [52]. No published studies were identified from either in low-income-countries (LICs) or lower-middle-income countries (LMICs). 


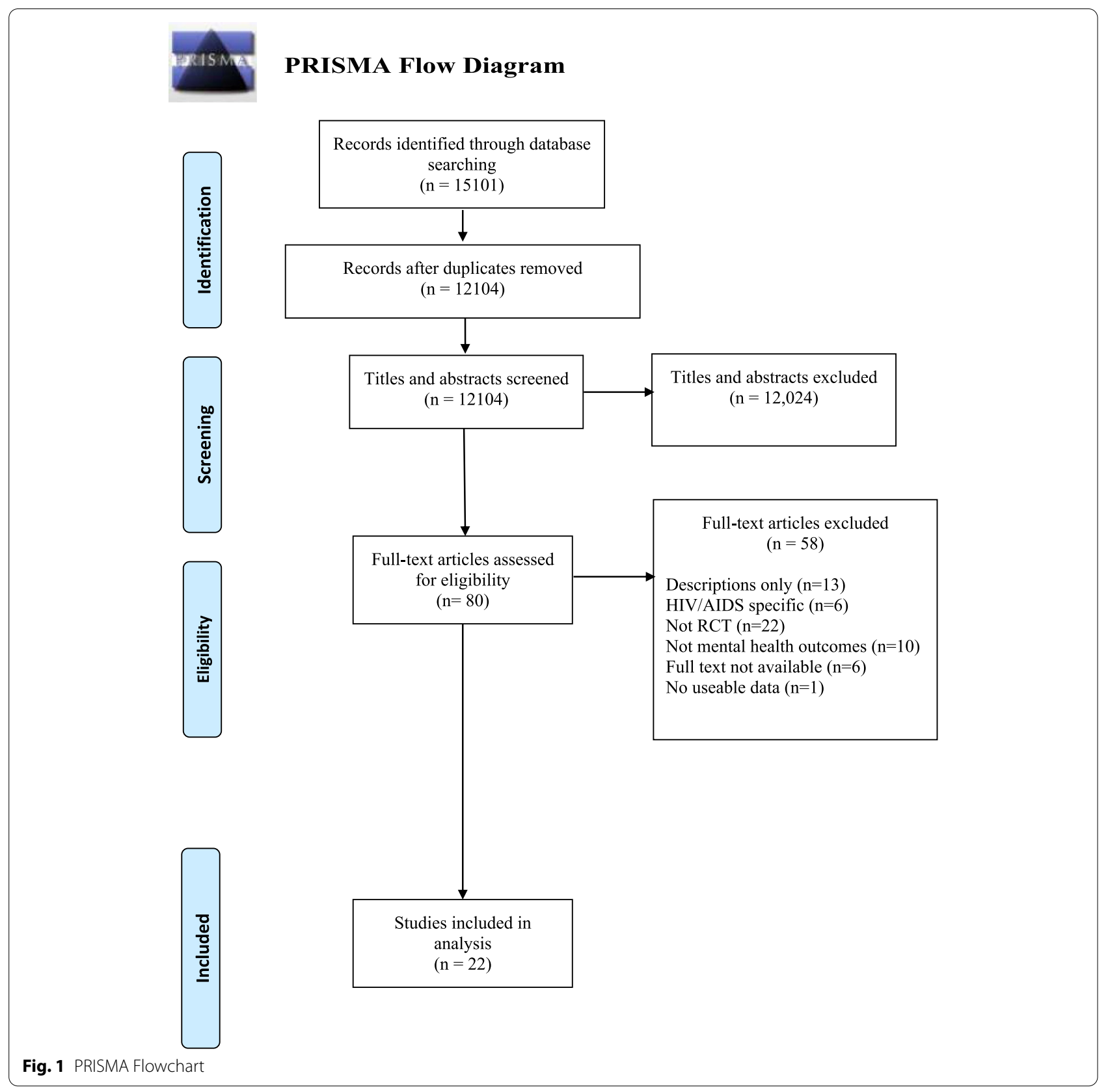

\section{Participant characteristics}

Patients

Eleven studies involved participants who were patients, of which: seven involved patients with COVID-19 [39, $40,42-44,47,48]$; three with pre-existing chronic diseases exposed to COVID-19 and / or with a diagnosis of COVID-19 [41, 52, 53]; and one involved adult patients with chronic diseases exposed to SARS [46].

\section{General population}

Seven studies involved participants from general populations exposed to COVID-19 [35, 36, 45, 51, 54-56]. Two of these seven studies involved schoolchildren [45, $56]$ and one involved college students [51]. 


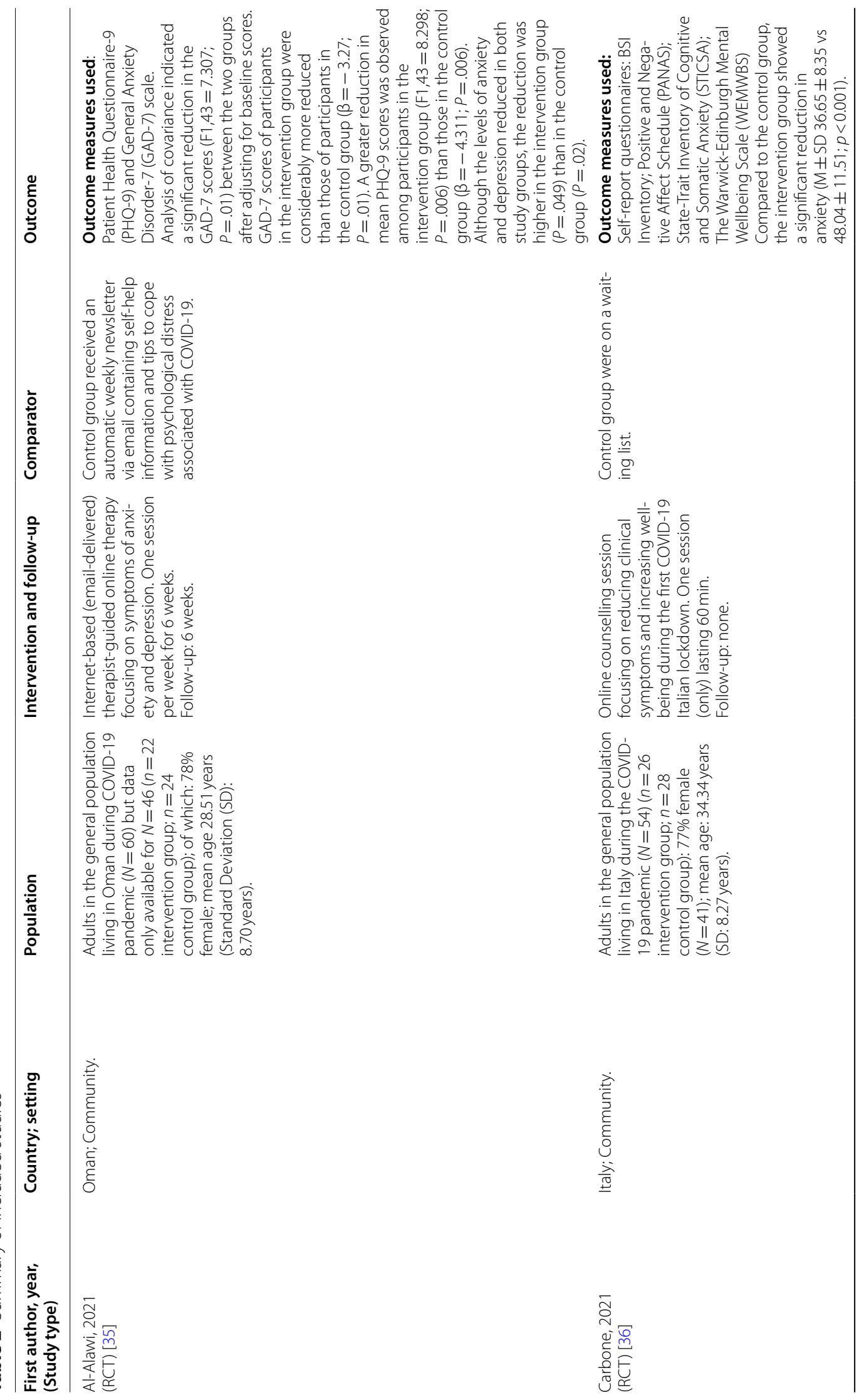




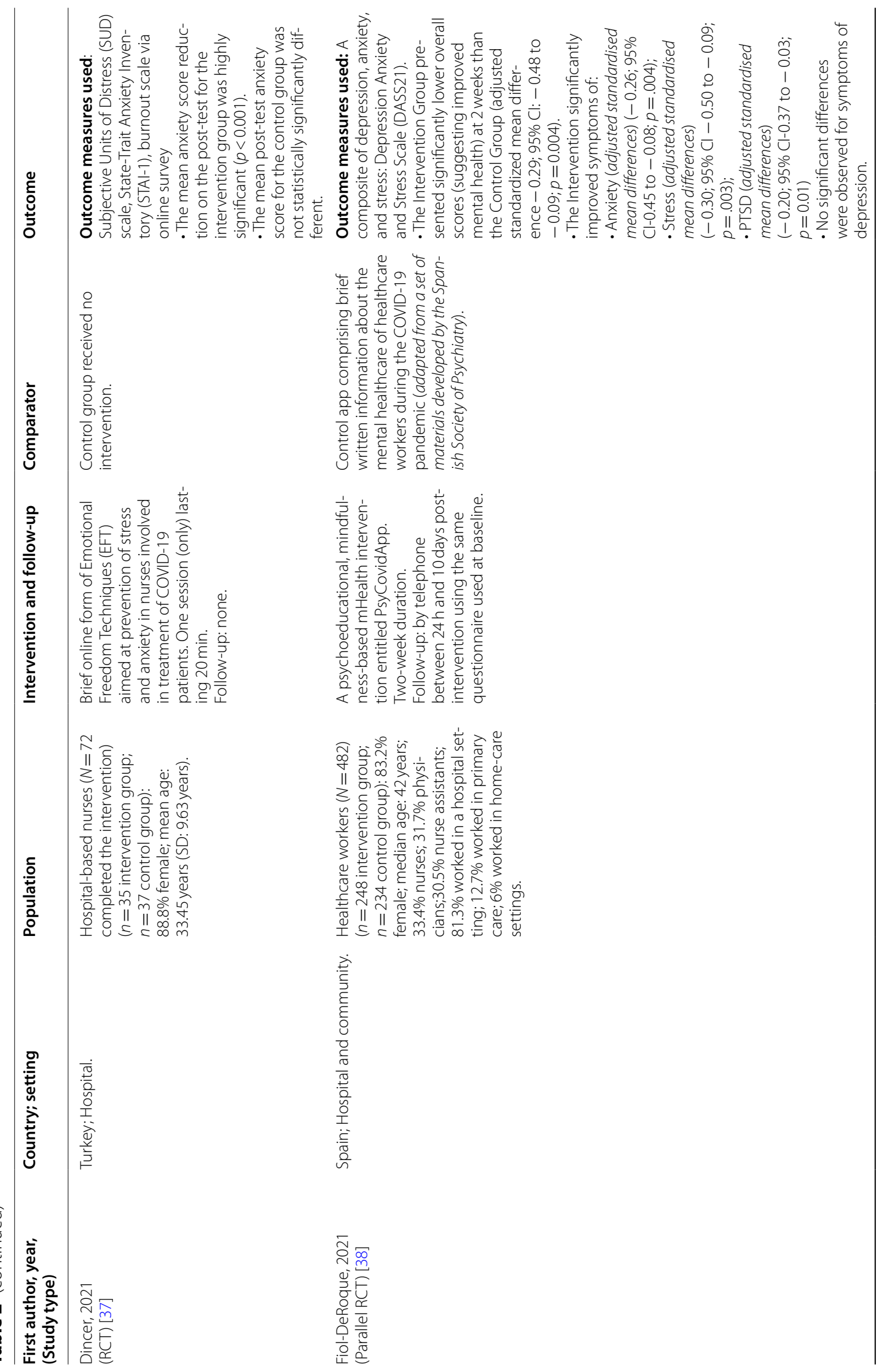




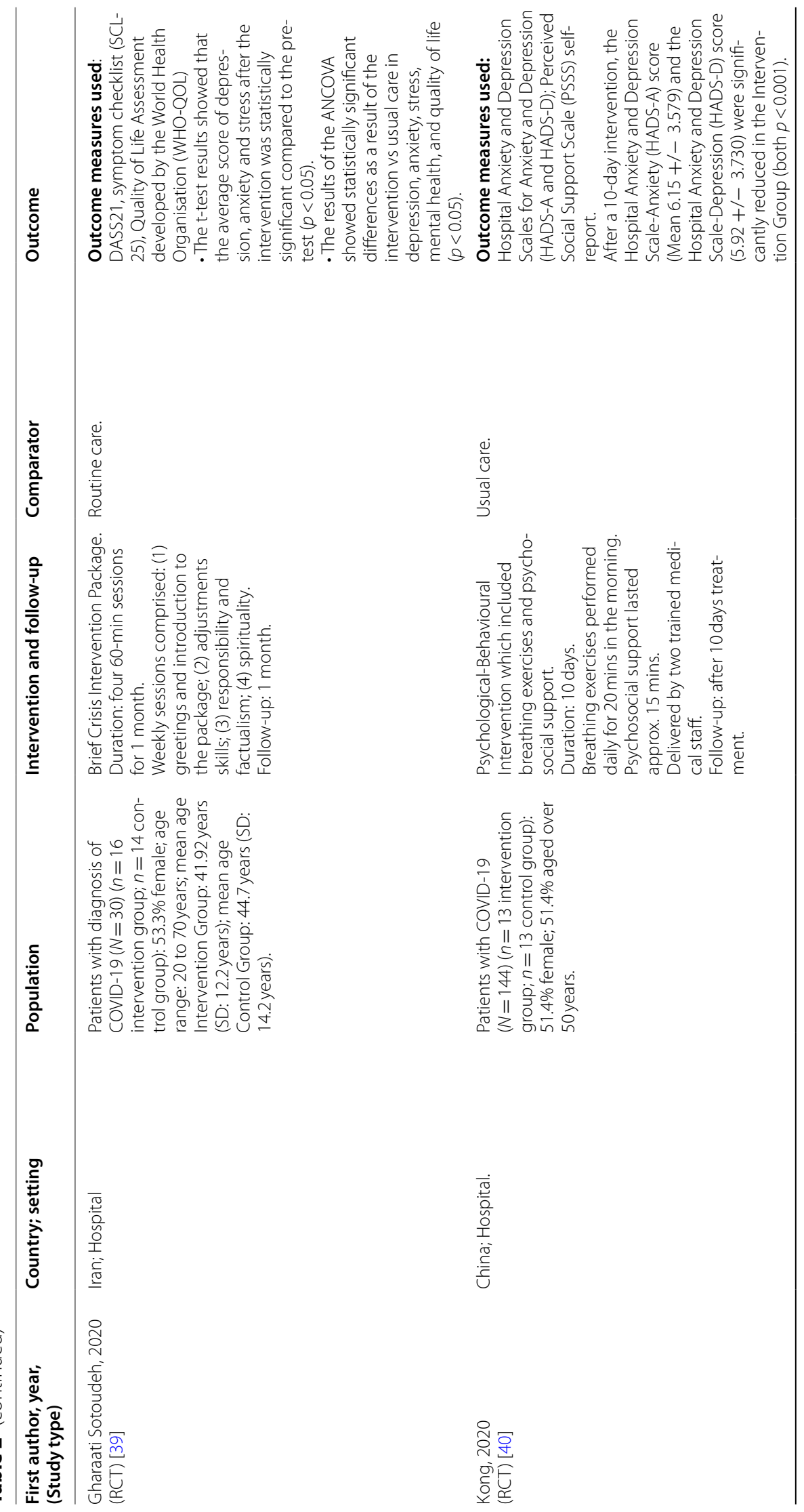




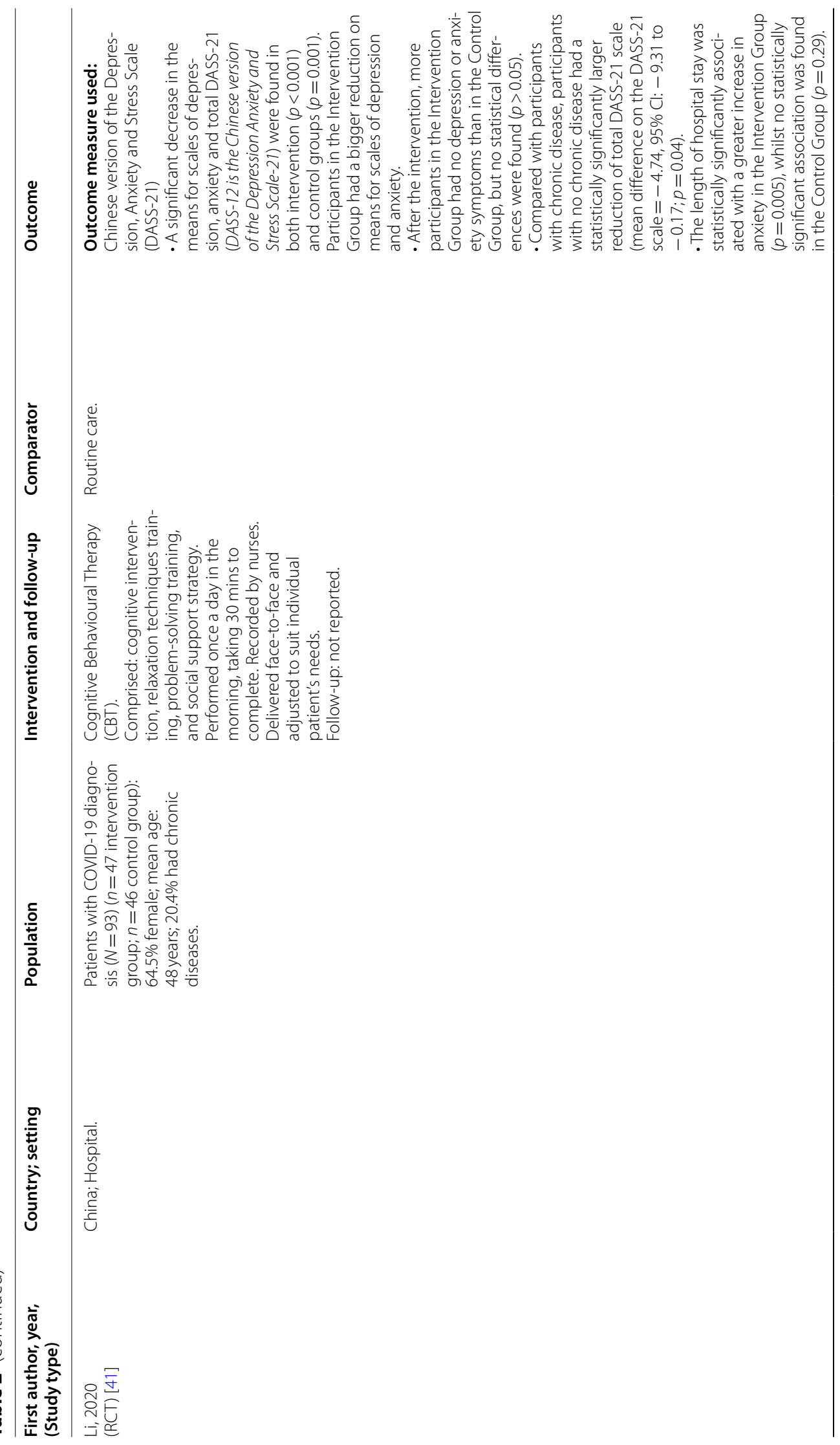




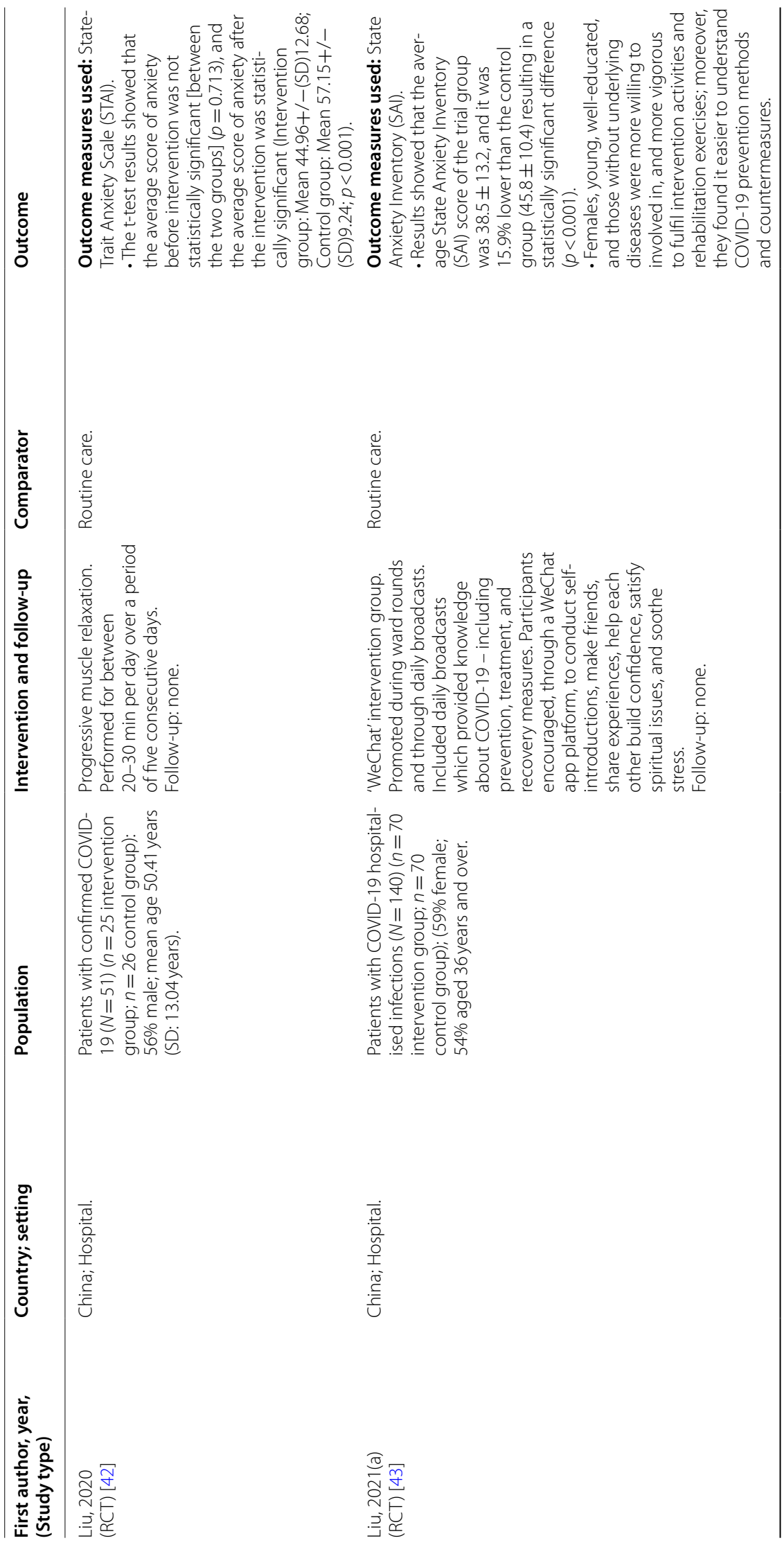




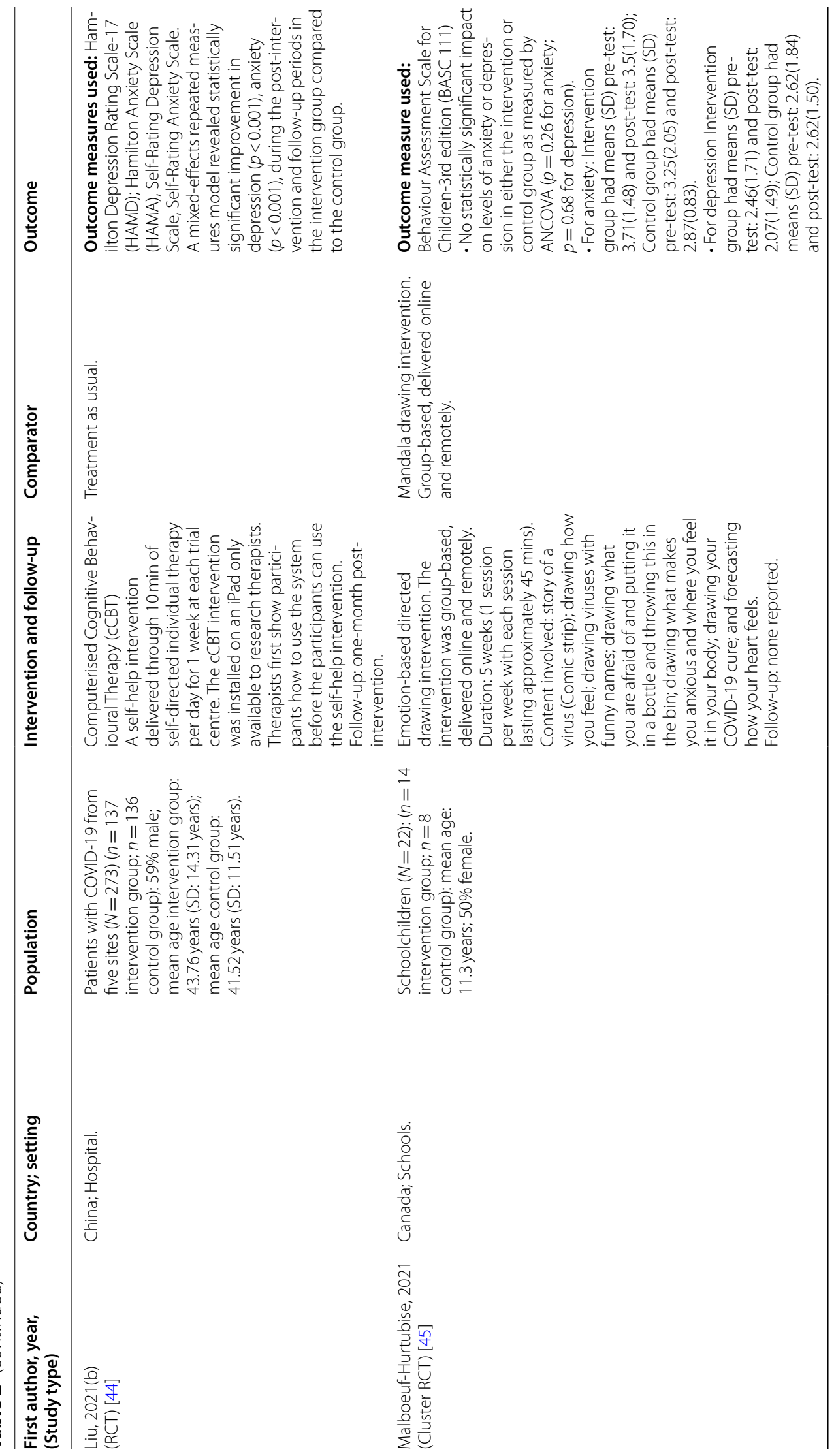




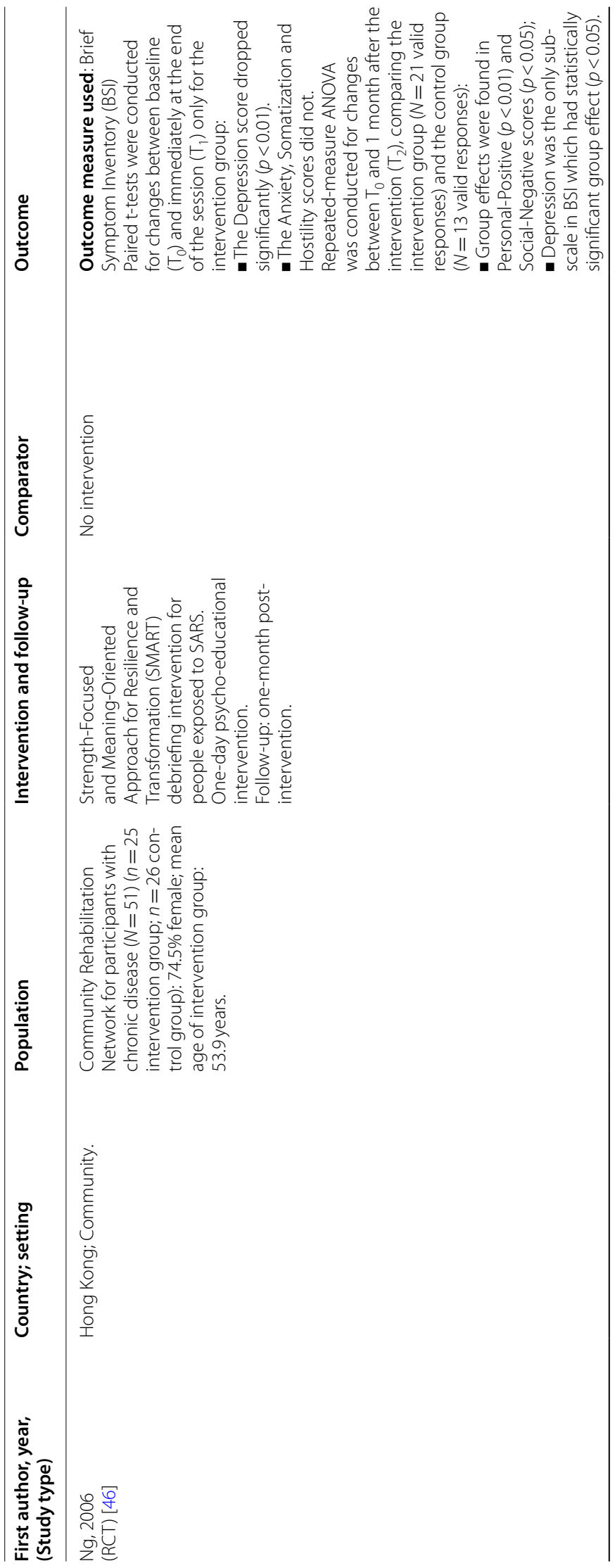




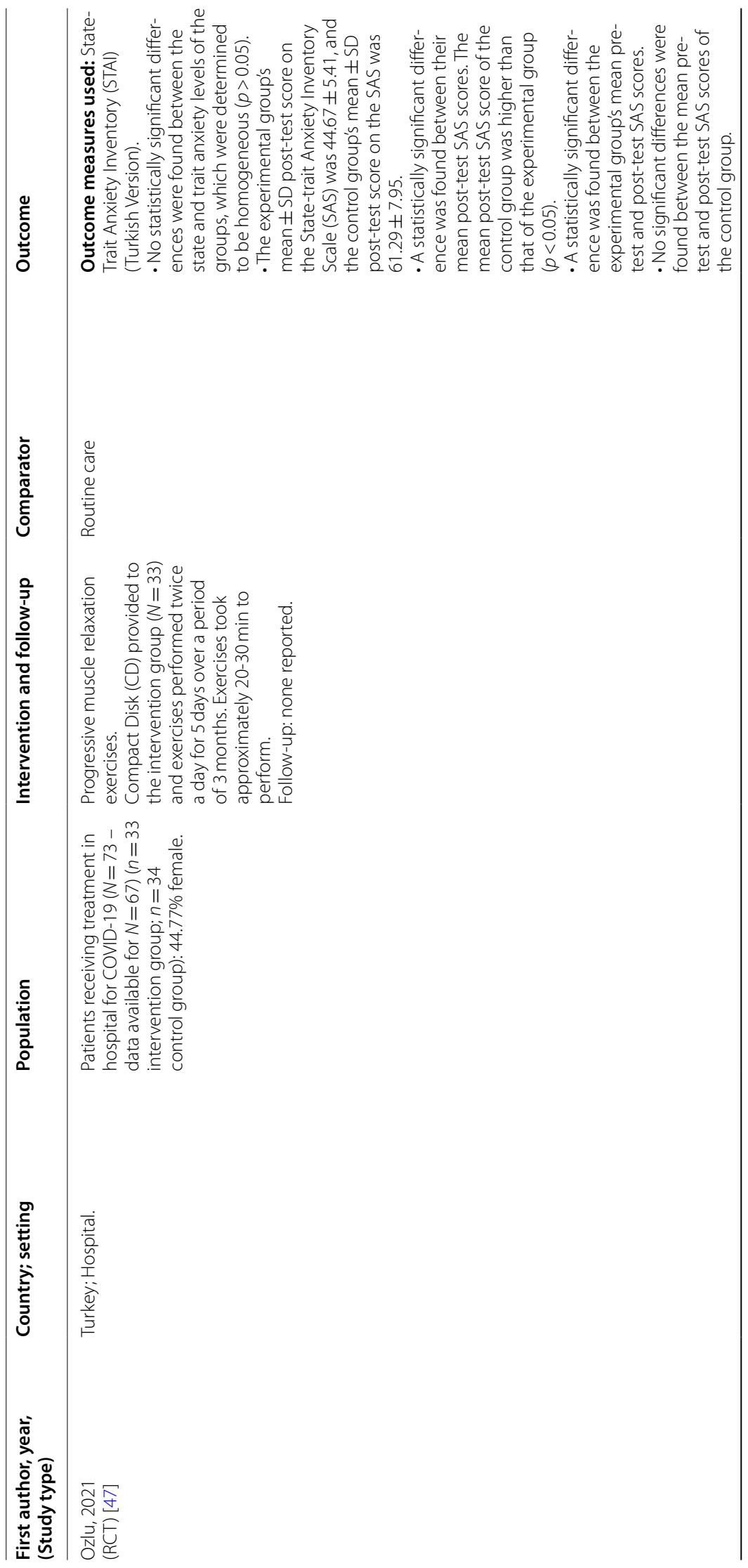




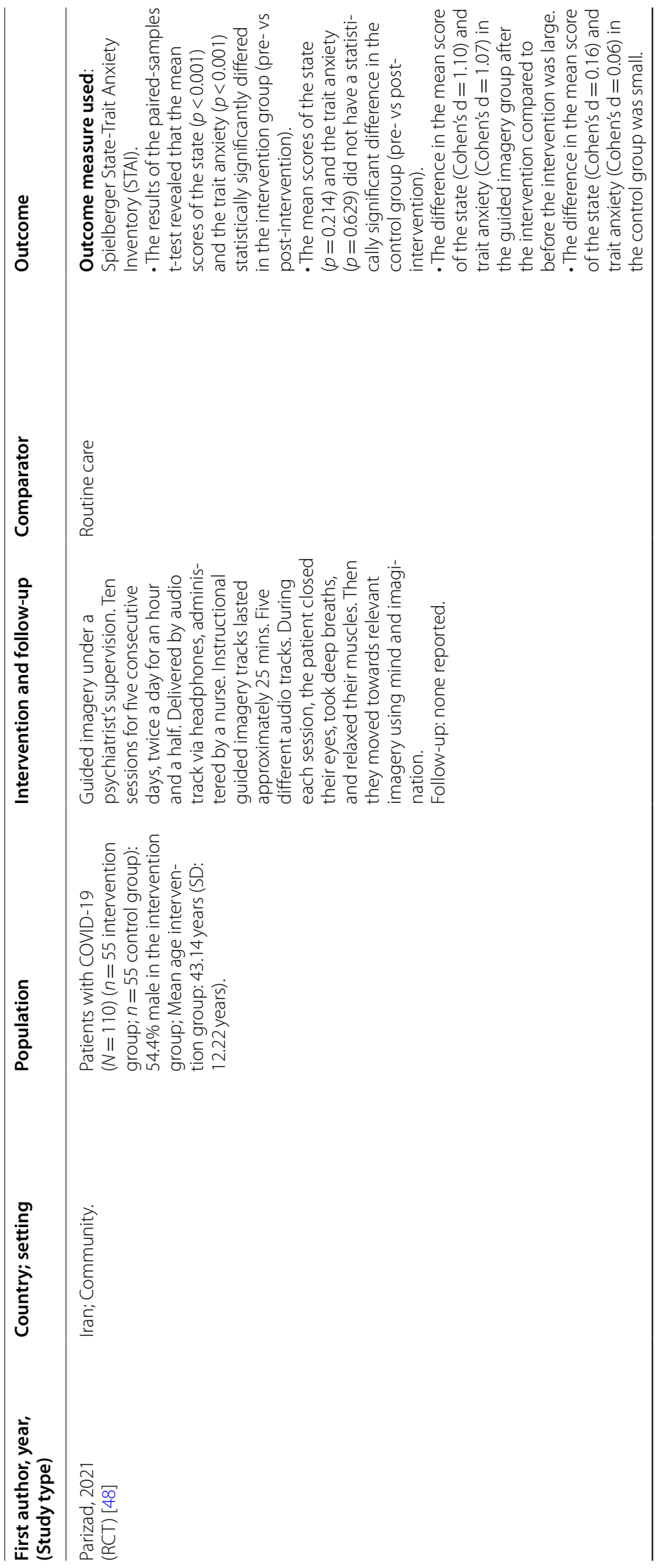




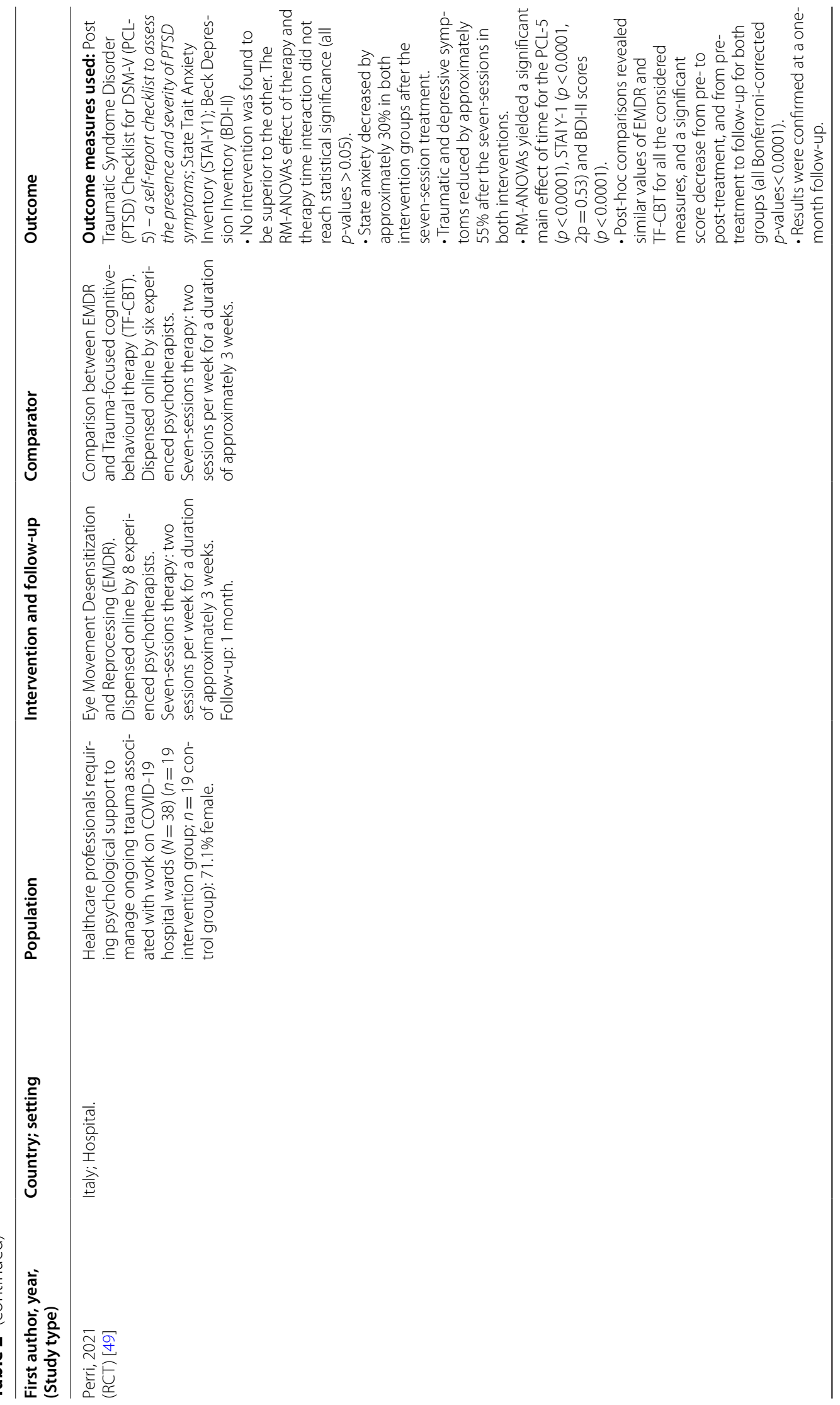




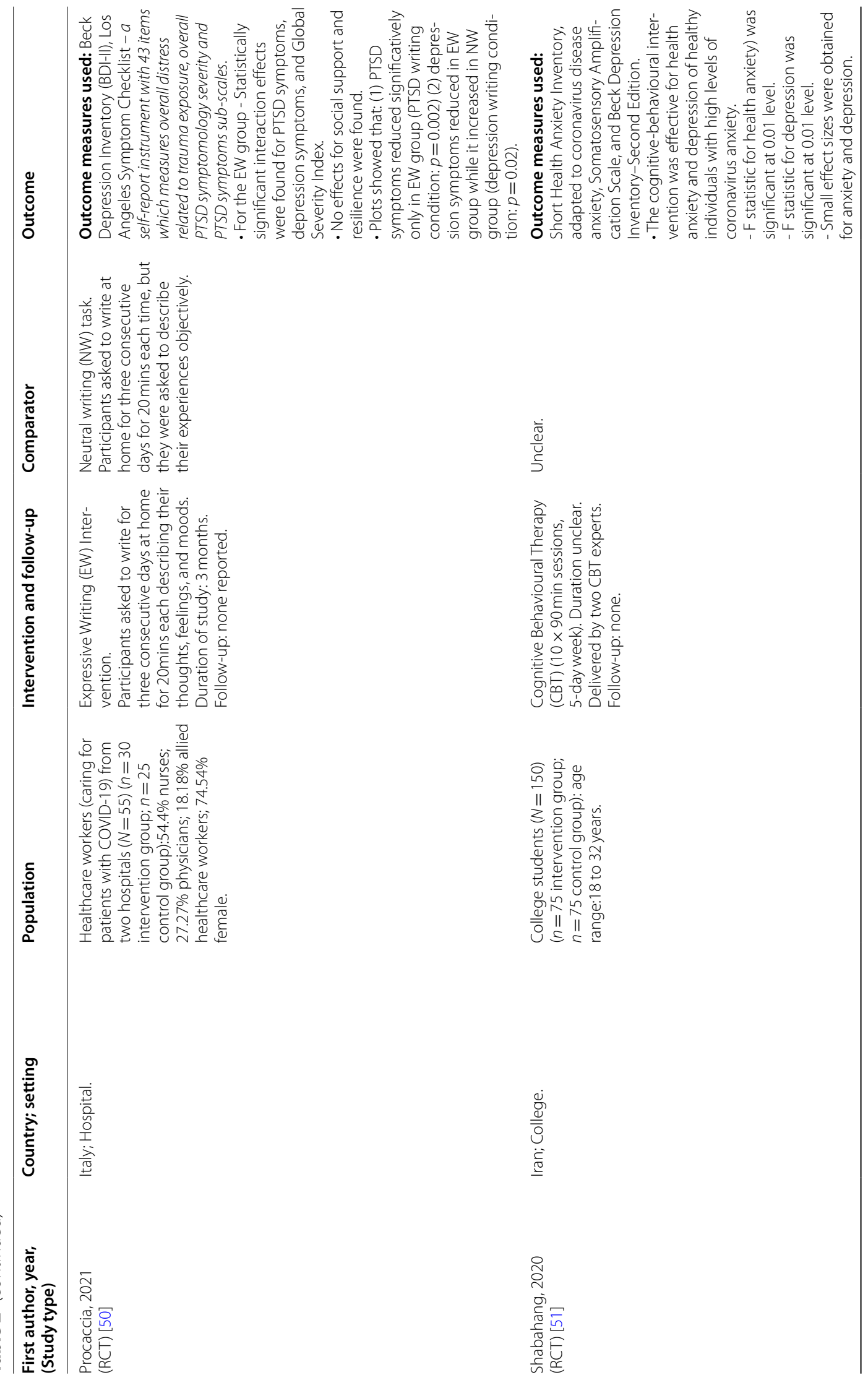




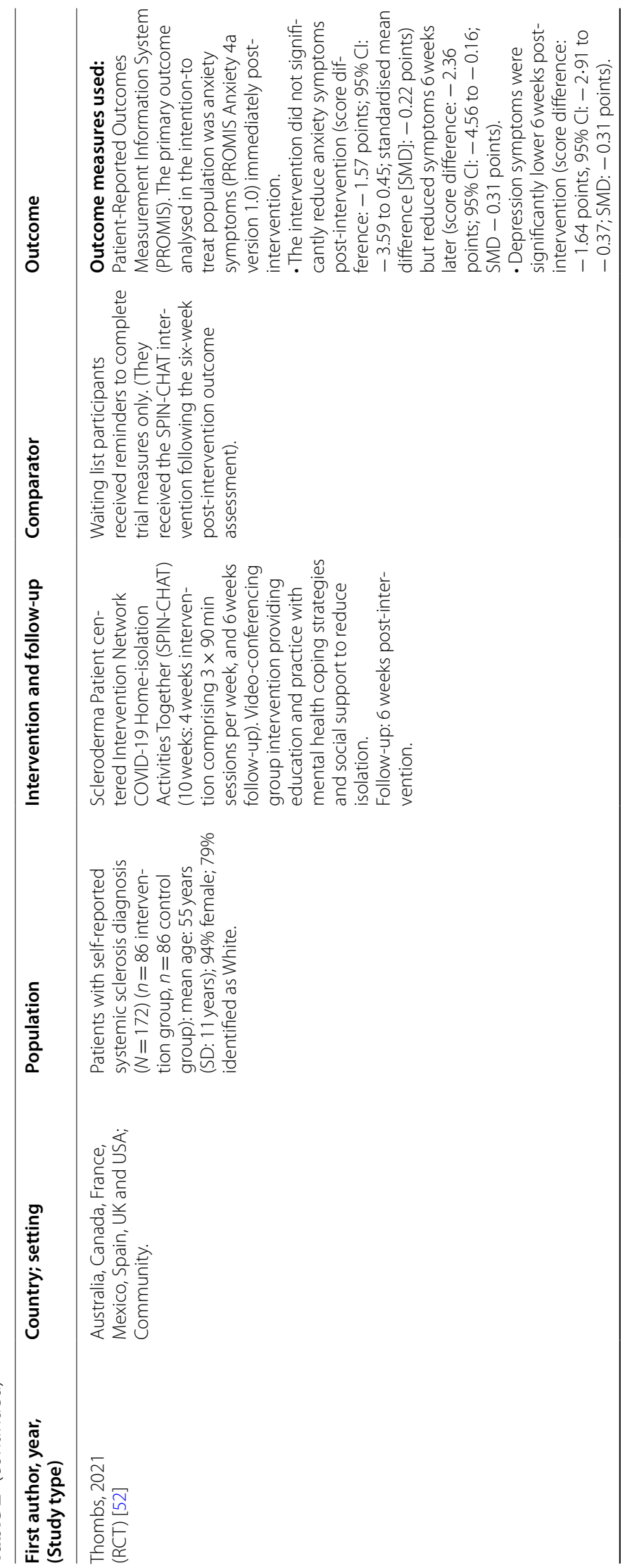




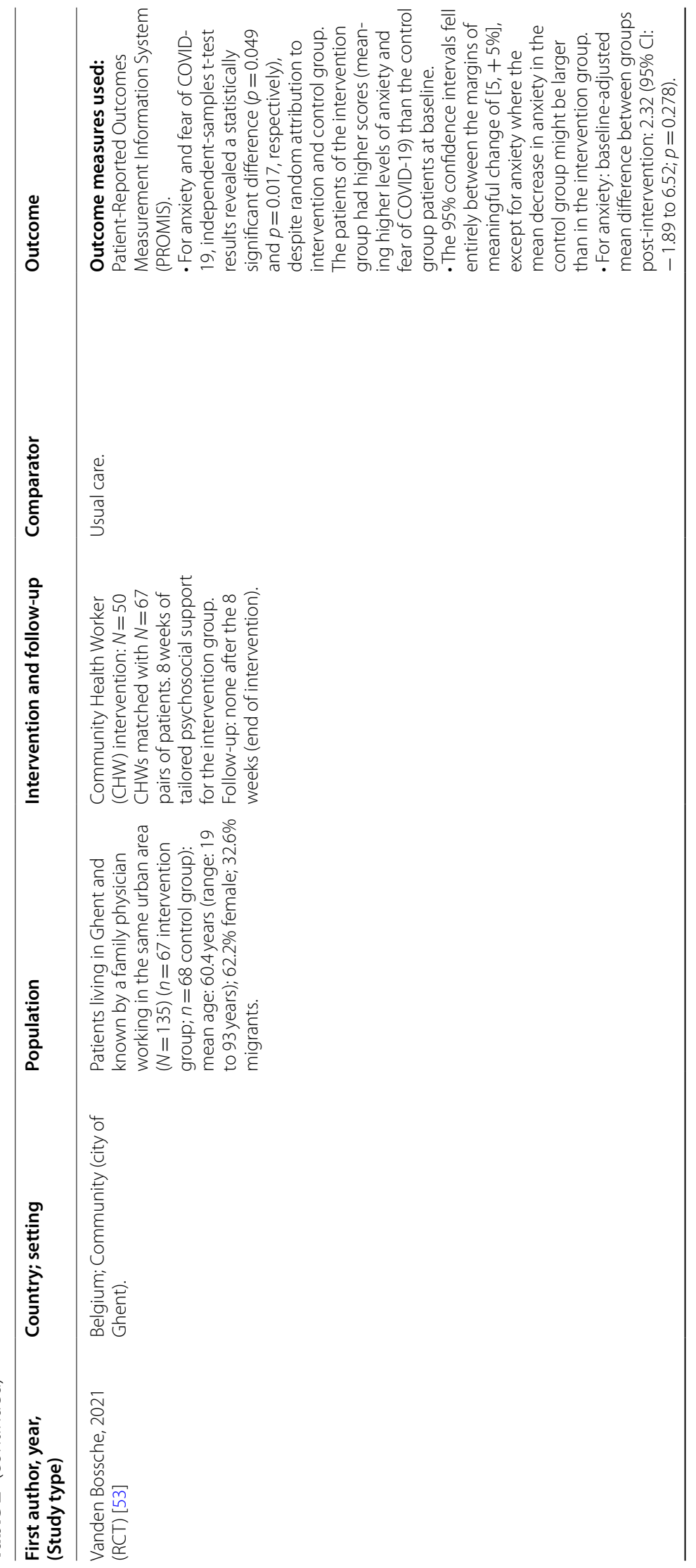




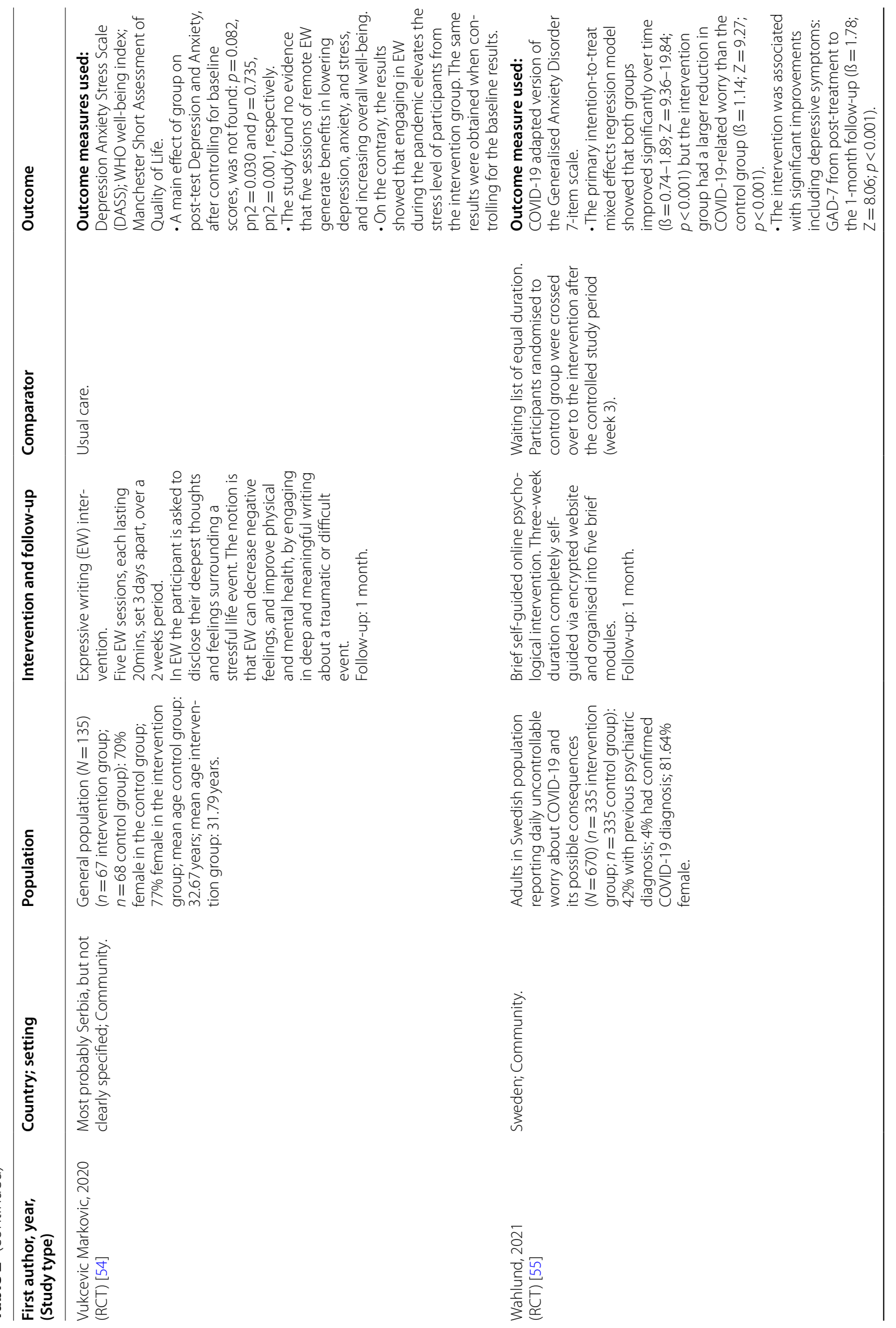




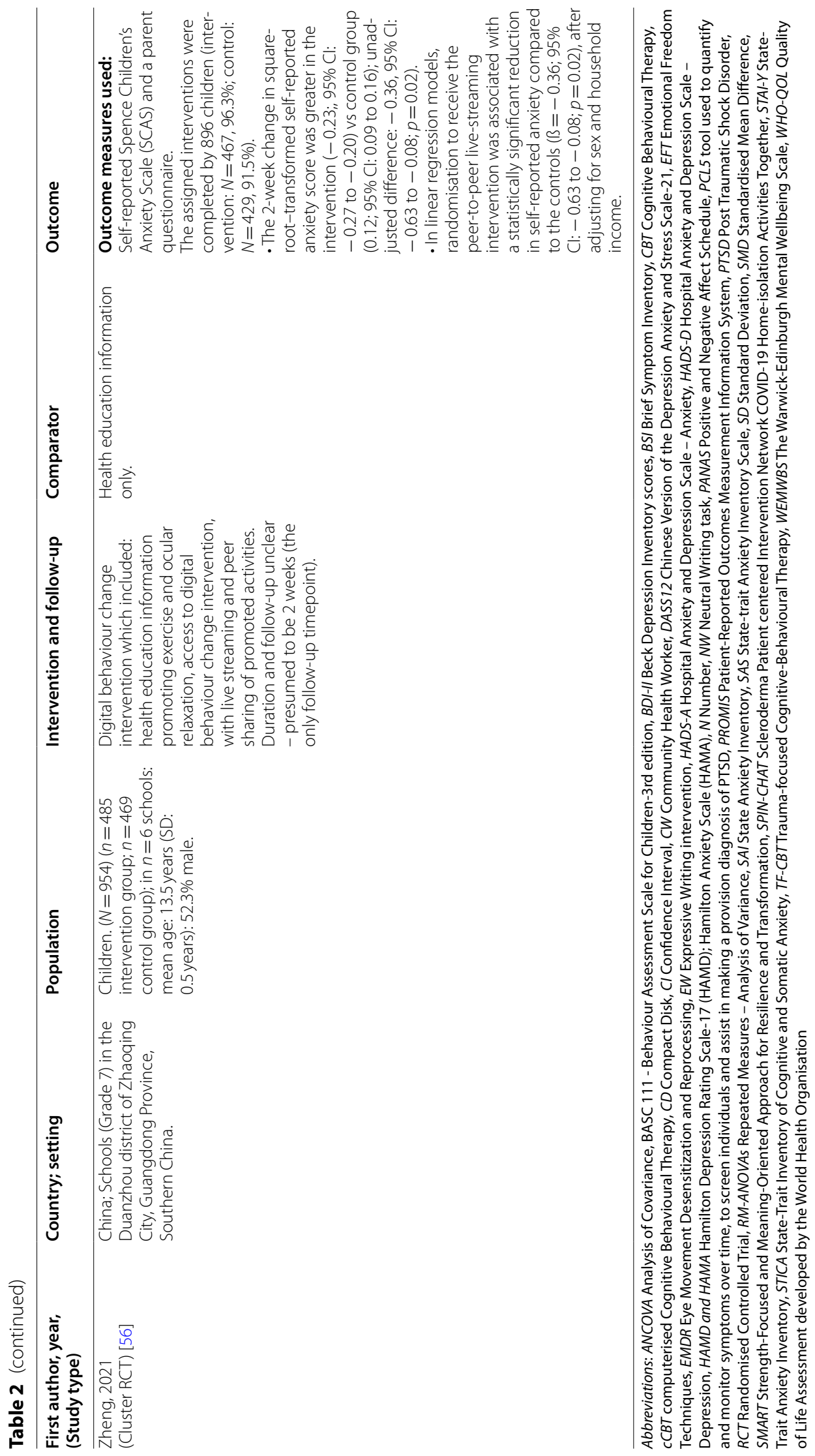


Table 3 Risk of bias (RoB2) assessments for studies included in the systematic review of the effectiveness of psychological support interventions for those exposed to mass outbreaks

\begin{tabular}{|c|c|c|c|c|c|c|c|}
\hline Study & $\begin{array}{l}\text { Domain } 1 . \\
\text { RoB from } \\
\text { randomization } \\
\text { process }\end{array}$ & $\begin{array}{l}\text { Domain 2: } \\
\text { RoB due to } \\
\text { deviations } \\
\text { from intended } \\
\text { interventions } \\
\text { (effect of } \\
\text { assignment to } \\
\text { intervention) }\end{array}$ & $\begin{array}{l}\text { Domain 2: } \\
\text { RoB due to } \\
\text { deviations } \\
\text { from intended } \\
\text { interventions } \\
\text { (effect of } \\
\text { adhering to } \\
\text { intervention) }\end{array}$ & $\begin{array}{l}\text { Domain } \\
\text { 3: Missing } \\
\text { outcome data }\end{array}$ & $\begin{array}{l}\text { Domain } 4: \text { RoB } \\
\text { in measurement } \\
\text { of outcomes }\end{array}$ & $\begin{array}{l}\text { Domain 5: RoB } \\
\text { in selection of } \\
\text { reported result }\end{array}$ & $\begin{array}{l}\text { Overall } \\
\text { risk of bias } \\
\text { judgement }\end{array}$ \\
\hline $\begin{array}{l}\text { Al Alawi, } 2021 \\
\text { [35] }\end{array}$ & + & $?$ & + & + & $?$ & + & $?$ \\
\hline $\begin{array}{l}\text { Carbone, } 2021 \\
{[36]}\end{array}$ & + & + & + & + & $?$ & $?$ & $?$ \\
\hline Dincer, 2021 [37] & $?$ & $?$ & + & + & + & + & $?$ \\
\hline $\begin{array}{l}\text { Fiol-DeRoque, } \\
2021 \text { [38] }\end{array}$ & + & $?$ & $?$ & + & + & + & $?$ \\
\hline $\begin{array}{l}\text { Gharaati Sotou- } \\
\text { deh, } 2020 \text { [39] }\end{array}$ & $?$ & $?$ & - & - & $?$ & + & - \\
\hline Kong, 2020 [40] & + & $?$ & - & + & + & + & $?$ \\
\hline Li, 2020 [41] & + & $?$ & $?$ & + & + & + & $?$ \\
\hline Liu, 2020 [42] & + & $?$ & + & + & $?$ & $?$ & - \\
\hline Liu Y, 2021(a) [43] & $?$ & $?$ & + & + & $?$ & $?$ & - \\
\hline Liu Z, 2021 (b) [44] & $?$ & $?$ & + & + & $?$ & $?$ & - \\
\hline $\begin{array}{l}\text { Malboeuf-Hur- } \\
\text { tubise, } 2021 \text { [45] }\end{array}$ & - & $?$ & $?$ & $?$ & $?$ & $?$ & - \\
\hline $\mathrm{Ng}, 2006$ [46] & + & $?$ & $?$ & - & - & $?$ & - \\
\hline Ozlu, 2021 [47] & + & $?$ & + & + & $?$ & $?$ & - \\
\hline Parizad, 2021 [48] & + & $?$ & + & + & $?$ & $?$ & - \\
\hline Perri, 2021 [49] & $?$ & $?$ & + & $?$ & $?$ & $?$ & - \\
\hline $\begin{array}{l}\text { Procaccia, } 2021 \\
\text { [50] }\end{array}$ & $?$ & $?$ & + & $?$ & $?$ & $?$ & - \\
\hline $\begin{array}{l}\text { Shabahang, } 2020 \\
\text { [51] }\end{array}$ & + & + & + & + & $?$ & $?$ & $?$ \\
\hline $\begin{array}{l}\text { Thombs, } 2021 \\
\text { [52] }\end{array}$ & + & + & $?$ & $?$ & $?$ & + & - \\
\hline Vanden, 2021 [53] & + & + & + & + & $?$ & + & $?$ \\
\hline $\begin{array}{l}\text { Vukcevic, } 2020 \\
\text { [54] }\end{array}$ & + & + & + & + & + & + & + \\
\hline $\begin{array}{l}\text { Wahlund, } 2021 \\
\text { [55] }\end{array}$ & + & + & + & + & + & + & + \\
\hline Zheng, 2021 [56] & $?$ & $?$ & $?$ & + & + & + & - \\
\hline
\end{tabular}

Key:

+ Low risk of bias

- High risk of bias

? Some concerns

\section{Healthcare workers}

Four studies focused on healthcare workers caring for patients with COVID-19, specifically nurses and / or other hospital staff $[37,38,49,50]$. No studies included social care workers. Only one study included staff from primary care settings [38].

\section{Sample size}

Participant numbers ranged from 22 to 954 (average number of participants: 173). The total number of participants included in the review was 3814 . 


\section{Participant age and target population}

Seventeen studies provided detailed age-related data [35-39, 41, 42, 44-48, 52-56]. Participants' mean ages ranged from 11.3 years to 60.4 years. The average age of all 17 studies' participants was 39.58 years. All studies provided gender-related data except for one study [51]. Fifteen of the 21 studies providing data involved more female participants than male participants (range: 51 to 94\% female participants) [35-41, 43, 46, 49, 50, 52-56].

\section{Settings}

Eleven studies were conducted in community-based settings $[35,36,45,46,48,51-56]$ and ten were conducted in hospitals [37, 39-44, 47, 49, 50]. One study included both hospital and community-based settings [38]. Only one study included primary care and long-term care facility settings [38].

\section{Interventions}

All studies investigated psychological mental health (support) interventions for participants exposed to COVID19 and / or with a diagnosis of COVID-19 apart from one, which examined interventions for adult patients with chronic medical conditions exposed to SARS [46].

\section{Interventions for patients}

Ten studies examined specific interventions for patients [39-44, 47, 48, 52, 53]. These interventions included: a brief crisis mental health intervention package [39]; a psychological behavioural intervention [40]; Cognitive Behaviour Therapy [41]; progressive muscle relaxation exercises [42, 47]; a group intervention [43]; computerised Cognitive Behavioural Therapy [44]; guided imagery under a psychiatrist's supervision [48]; a tailored intervention and group app 'SPIN-CHAT' for patients with a chronic medical condition [52]; and a Community Health Worker intervention [53]. One study explored a culturally specific debriefing intervention for patients with chronic disease following a SARS outbreak [46].

\section{Interventions for the general population}

Seven studies investigated interventions for the general population [35, 36, 45, 51, 54-56]. These included: an internet-based therapist-guided online therapy focusing on symptoms of anxiety and depression in adults in the general population exposed to COVID-19 [35]; an online counselling session focusing on reducing clinical symptoms and increasing wellbeing amongst adults during the first COVID-19 lockdown in Italy [36]; an emotion-based directed drawing intervention for schoolchildren [45]; Cognitive Behavioural Therapy sessions for college students [51]; an Expressive Writing intervention for adults [54]; a brief self-guided online psychological intervention for adults reporting uncontrollable worry about COVID19 [55]; and a digital behaviour change intervention aimed at reducing anxiety in schoolchildren [56].

\section{Interventions for healthcare workers}

Four studies explored interventions for healthcare workers exposed to COVID-19 [37, 38, 49, 50]. These interventions included: a brief (one online session lasting $20 \mathrm{~min}$ ) form of an Emotional Freedom Techniques aimed at the prevention of stress and anxiety in nurses involved in the treatment of COVID-19 patients [37]; a psychoeducational mindfulness-based mHealth intervention for healthcare workers (nurses, physicians, and nursing assistants) working in either a hospital-based setting, primary care or homecare setting during the COVID-19 pandemic [38]; an Eye Movement Desensitization and Reprocessing (EMDR) intervention for healthcare workers working on COVID-19 hospital wards [49]; and an Expressive Writing intervention for healthcare workers (nurses, physicians and allied healthcare workers) caring for COVID-19 patients in hospital [50].

Twelve interventions were delivered remotely either online via the internet, by mobile phone apps, audiorecordings or by video-conferencing facilities $[35,36,38$, $43-45,48,49,52,54-56]$. One intervention involved the use of an audio-recording played under supervision [47], and one intervention involved a writing task conducted alone at home [50]. The remainder were delivered in person (face-to-face).

Eight studies included a 4-6 weeks post-intervention follow-up period [35, 39, 44, 46, 49, 52, 54, 55]. Two studies included a 24 -h to 10 days post-intervention follow-up $[38,40]$. Six studies had no post-intervention follow-up $[36,37,42,43,51,53]$. The follow-up for the remaining six studies was unclear $[41,45,47,48,50,56]$.

\section{Comparators}

All studies included comparators which were either: no intervention [37, 46]; routine (usual) care [39-44, 47, $48,53,54]$; waiting lists [36, 52, 55]; a newsletter or brief written (health related) information (only) [35, 38]; a different psychological support intervention [45, 49]; or a neutral task e.g. neutral writing task instead of an expressive writing intervention $[50,56]$. The comparator in one study was unclear [51].

\section{Meta-analysis}

Meta-analyses, involving all but two of the included studies $[43,46]$, showed that psychological interventions had a statistically significant benefit in managing depression (Standardised Mean Difference [SMD]: -0.40; 95\% Confidence Interval $[\mathrm{CI}]:-0.76$ to -0.03 ) (Fig. 2) and anxiety (SMD: -0.72 ; $95 \% \mathrm{CI}:-1.03$ to -0.40 ) (Fig. 3). The 
Doherty et al. BMC Psychiatry

(2021) 21:592

Page 23 of 28

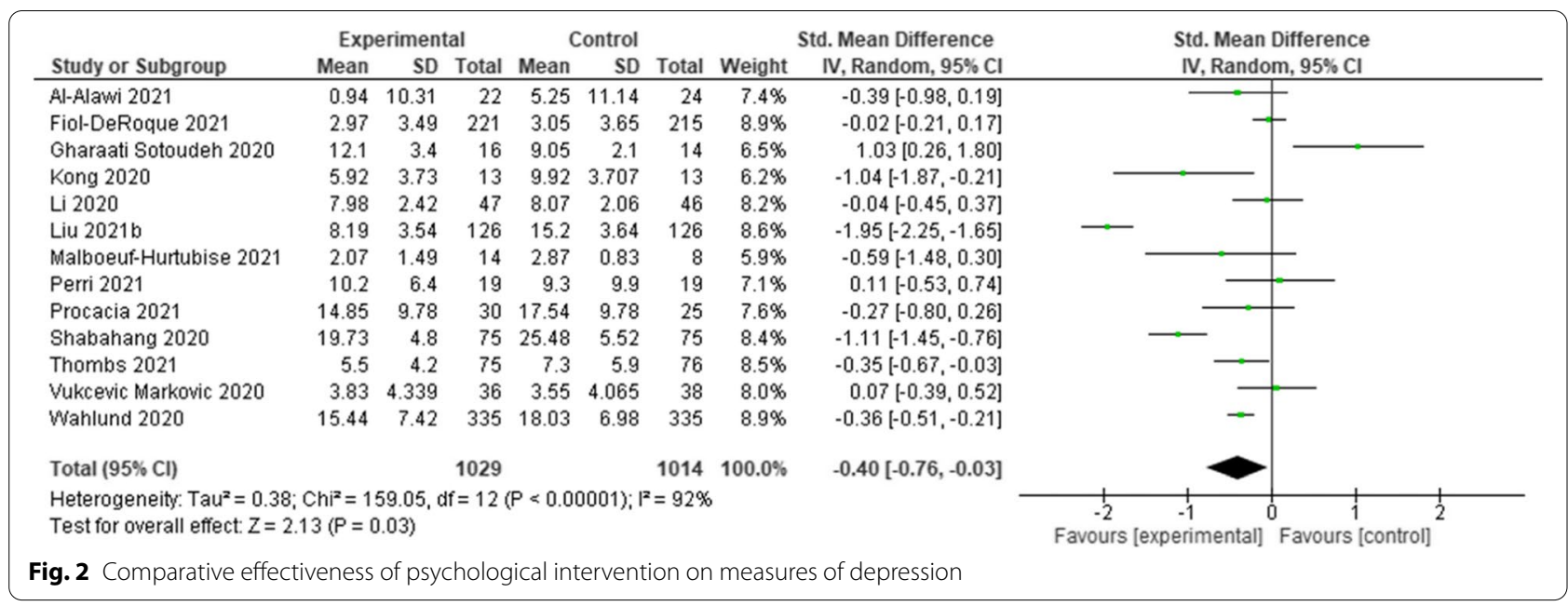
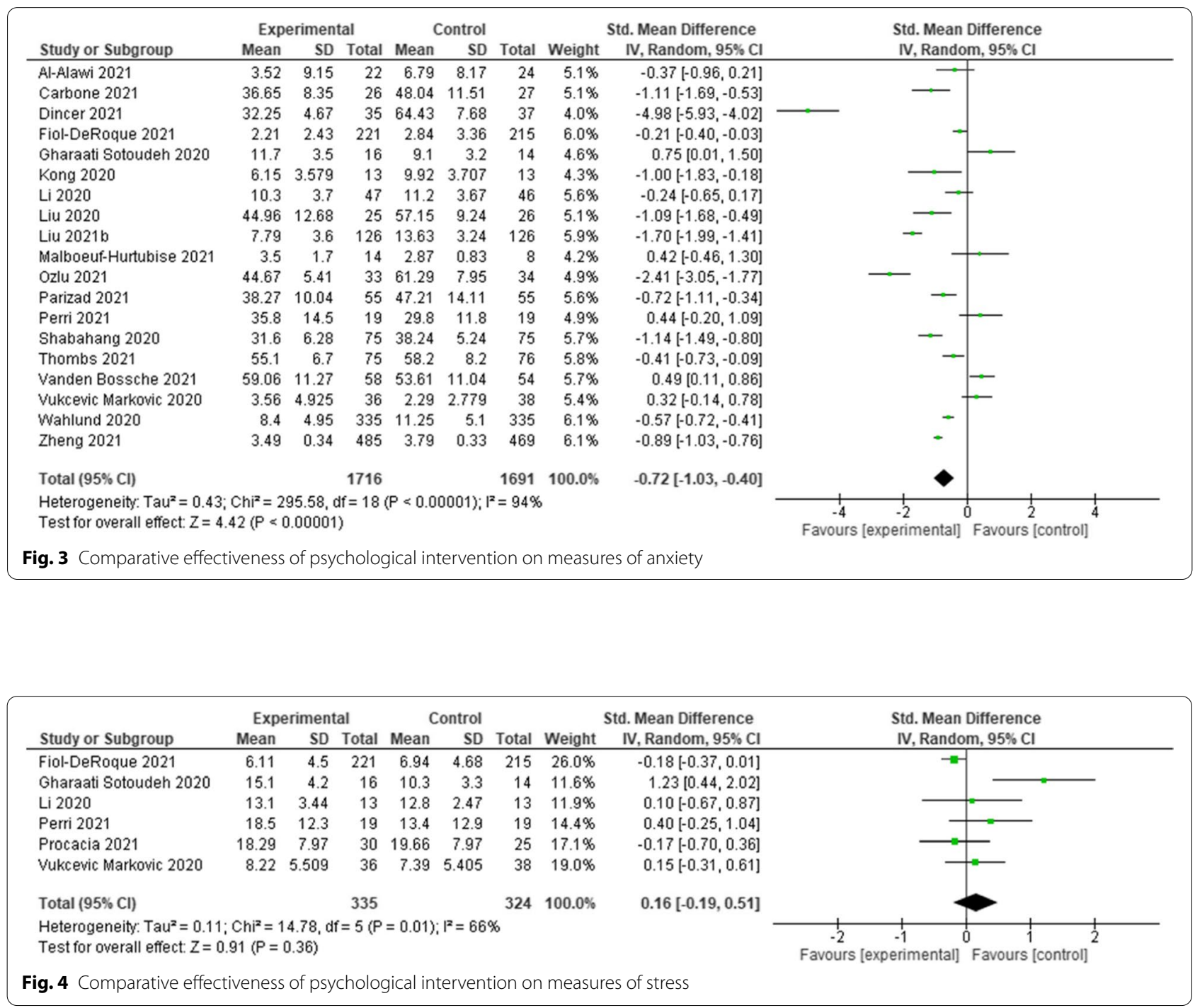
effect on stress was equivocal (SMD: 0.16; 95\% CI: -0.19 to 0.51 ) (Fig. 4). All analyses were affected by substantial or considerable heterogeneity $\left(\mathrm{I}^{2} 92 \%\right.$ (depression); $\mathrm{I}^{2}$ 94\% (anxiety); and $\mathrm{I}^{2}$ 66\% (stress)). The two studies excluded from the meta-analysis included culturally specific psychological interventions for patients with mild-COVID-19 [43], and patients with chronic diseases following a SARS outbreak [46]. These studies reported benefits in managing anxiety [43]; and depression [46].

\section{Sensitivity and sub-group analyses}

Sensitivity analyses were also conducted, removing studies which appeared to skew the findings [37, 39] for depression, anxiety and stress (Additional file 3). Although heterogeneity was markedly reduced for the meta-analysis of stress outcome, it had limited effect on both the heterogeneity associated with the analyses of depression and anxiety and the pooled effect measures for all outcomes.

Sub-group post-hoc analyses were conducted after looking at the review's data to investigate the influence of different participants, the setting of the interventions and the RCTs' risk of bias (Additional file 3). Heterogeneity continued to affect the different sub-groups, with limited variation in the outcomes from the original meta-analyses. It was evident from the sub-group analysis based on risk of bias, that studies of depression and anxiety that were at a higher risk of bias tended to report greater benefit from the intervention. However, as most of the metaanalyses were affected by considerable heterogeneity, they should be interpreted cautiously.

\section{Discussion}

This is the first systematic review which aimed to identify the types of psychological (mental health) interventions which have been used either in previous mass infectious disease outbreaks (similar to COVID-19) or during the COVID-19 pandemic to support the general population and healthcare workers, and to assess how effective they have been. The meta-analyses conducted suggest that different psychological support interventions have shown potential effectiveness to reduce levels of anxiety and depression in those exposed to mass infectious disease, but not for levels of stress. This finding supports other sources which argue that whilst individuallydirected psychological interventions are associated with some reductions in mental health conditions such as depression and anxiety, there needs to be a more holistic approach which includes both personalised interventions and organisational-level and societal structural changes to decrease stressors associated with a mass outbreak [10-12]. For example, healthcare workers continuously working long hours in stressful and resource constrained settings [12] require organisational-level interventions to improve their working environments and thereby decrease associated stressors, yet there is limited evidence of preventative measures or organisational level interventions [10]. Also, prior to a mass outbreak, members of the general population may already have experienced an ongoing lack of mental health service provision, but this gap has been exacerbated during the COVID-19 pandemic [10-12]. Wider public mental health provision should, therefore, be included in national preparedness and emergency response plans for mass infectious disease outbreaks [10-12].

Many of the interventions identified by this review were delivered remotely e.g. online or by a mobile phone app rather than in person. Such resources may be helpful in helping in managing and coping with the mental health impacts arising from a mass outbreak. Establishing more online mental health services in hospitals and communities could be an opportunity to address the shortage of mental health care service provision for the general population and healthcare workers [12]. However, further studies are needed to explore their effectiveness and their acceptability to the recipients. Consideration is also needed for all those who may not have access to online digital resources and / or support to help them access these resources.

Our review found a lack of RCTs with representative study populations including: insufficient studies involving healthcare workers $(n=4 / 22)$; none involving social care workers; few involving children and young people $(n=2 / 22)$; few involving primary care staff $(n=1 / 22)$; a lack of studies involving male participants $(n=15 / 22$ studies involved higher percentages of female participants); and no studies from LICs or LMICs.

Many of the interventions were brief, involving small sample sizes and with little or no longer-term followup: 12 studies had no follow up or they did not report on their follow-up. The longest follow-up period postintervention was 6 weeks. Most of the studies were assessed as being of high risk of bias, which appeared to affect outcomes. Some of the brief interventions involved participants re-living past traumatic experiences. Brief single-session debriefing interventions that focus on reliving past experiences for those who have experienced a traumatic event are not recommended as they may increase their risk of depression and Post Traumatic Shock Disorder (PTSD) [20,57].

An influenza pandemic of unprecedented scale was expected many years before the outbreak of COVID-19 [1-5]. The likely impact and the need for psychological interventions to support and build the resilience of those exposed were also known $[11,13]$. Despite this, our review found a lack of published evidence exploring 
the effectiveness of psychological interventions for those exposed to such mass infectious disease outbreaks. Most of the evidence identified by the review was related to COVID-19 and published in the last 15 months. This suggests that lessons have not been learnt from previous mass infectious disease outbreaks. The focus of previous published research may have been concerned with a focus on the mass outbreak itself and not with its wider consequences on mental health outcomes; or it may have been concerned with exploring interventions for those exposed to man-made or natural disasters such as war or earthquakes; or it may have been concerned with only certain population groups such as healthcare workers (only) or children (only). We acknowledge that the current pandemic is rapidly evolving globally, as is the evidence base. We also acknowledge that organisations may already provide interventions for mass infectious disease outbreaks, but that the effectiveness of these interventions may have not been formally evaluated in a mass outbreak setting. For example, NHS England commissioned resilience hubs for healthcare staff in late 2020 [58]. The effectiveness and acceptability of these hubs will need evaluating. There may be interventions that, while used in other situations (for example war settings), might have been used during the COVID-19 pandemic without prior testing in mass outbreak situations. It is not known if the types of interventions from other settings are effective in response to a mass outbreak such as COVID-19. Furthermore, findings from some relevant and ongoing COVID-19 related mental health support intervention trials may not have been published in peer-reviewed journals at the time of writing. In addition, the burden of care in the COVID-19 pandemic included staff working in long-term care home facilities and primary care staff as well as hospital-based staff. Our review found a dearth of research involving interventions for these staff. The implementation and impact of interventions in different healthcare workers and in different population groups may differ. Factors such as acceptability, access, take-up and timing of interventions for different healthcare and population groups are important considerations in trials and evaluations of complex interventions. Therefore, there are opportunities for further research including research to investigate whether interventions used in other large-scale disasters are comparable when used in response to a pandemic such as COVID-19, and to explore whether any organisations already offer any psychological interventions and to formally evaluate these.

This review's findings support the call for greater global action [59]. Psychological interventions are needed for all those affected by, and / or more vulnerable to, the mental health consequences of a mass outbreak including, for example:
* Children and young people experiencing anxiety and depression associated with the loss of freedom and opportunities for play, boredom, separation from friends, and school closures during lockdowns [28].

* Ethnic minorities: a survey of over 14,000 people from ethnic minorities revealed that existing inequalities in housing, employment, finances, and other issues have had a greater impact on their mental health than white people during the COVID-19 pandemic [27].

* Healthcare workers experiencing anxiety, depression, stress or PTSD as a consequence of caring for populations affected by a mass outbreak. Healthcare workers carry significant burdens during a mass outbreak, including a considerable impact on their psychological wellbeing. Therefore, supporting their mental health wellbeing should continue to be a priority $[8-10,19]$. This should include preventative measures as well as timely access to effective and acceptable psychological interventions where needed.

* People with disabilities such as those with learning disabilities, and those with pre-existing physical and mental health conditions during periods of shielding or self-isolation. The COVID-19 pandemic has exposed pre-existing health inequalities for people with mental health and learning disabilities [60]. * People experiencing mental health problems as a consequence of domestic violence. Domestic violence has increased during lockdowns as there is no escape from abusers [61].

All those affected need access to safe, appropriate, targeted evidence-based psychological interventions to support them both in the immediate and longer-term.

\section{Limitations}

Our review was limited to studies published in English and there may be other relevant studies published in other languages. We originally intended to include all study types in our review (as indicated within our published protocol). However, the evidence base has evolved rapidly, and we were able to identify new experimental controlled studies that theoretically provided more robust evidence. The following studies limitations impinge on their generalisability: small sample sizes; challenges regarding recruitment and retention of representative samples of participants (particularly for studies conducted during a pandemic); high risk of (or some concerns with) bias; and / or a lack of follow-up to estimate the longer-term effects of an intervention. Some studies relied solely on self-reporting measures and participants may have provided positive responses as they may have 
wanted to please the researchers and / or they may have possibly feared losing their jobs / or treatment if they gave negative responses (response bias). Only those interested in the research, who had the time, were accessible or were paid for their involvement may have participated. Some improvements in mental health may have been the result of other confounding factors.

\section{Conclusions}

Despite benefits from psychological interventions in managing anxiety and depression for all those exposed to mass infectious disease outbreaks, the evidence is limited. The review highlights the need for further research including complex intervention trials, studies involving representative study populations, studies to investigate whether interventions used in other large-scale disasters are effective when used during a pandemic such as COVID-19, and to explore whether any organisations already offer any psychological interventions, and to formally evaluate these. Research is needed now to inform the development and implementation of effective psychological interventions for all those exposed to mass infectious disease outbreaks to ensure we are adequately prepared. Intervention development, piloting, evaluating, reporting and implementation should follow recommended guidance for complex interventions $[62,63]$.

\begin{abstract}
Abbreviations
CBT: Cognitive Behavioural Therapy; COVID-19: Coronavirus; DASS-21: Depression, Anxiety and Stress Scale; EMDR: Eye Movement Desensitization and Reprocessing; GAD-7: Generalized Anxiety Disorder scale.; H1N1: A type of influenza A virus; HIC: High-income-country; LIC: Low-income-country; LMIC: Lower-middle-income-country; MERS: Middle East Respiratory Syndrome; PHQ-9: Patient Health Questionnaire depression scale.; PTSD: Post-Traumatic Shock Disorder; RCT: Randomised Controlled Trial; RoB2: Risk of bias assessment; SARS: Severe Acute Respiratory Syndrome; SARS-CoV-2: A virus that can cause COVID-19, a mass infectious disease; SMART: 'Strength-Focused and Meaning-Orientated Approach for Resilience and Transformation'; UMIC: Upper-middle-income-country.
\end{abstract}

\section{Supplementary Information}

The online version contains supplementary material available at https://doi. org/10.1186/s12888-021-03602-7.

Additional file 1. Search Strategy.

Additional file 2. Screening Tool.

Additional file 3. Sensitivity and sub-group meta-analyses.

\section{Acknowledgements}

The authors wish to acknowledge Alan Price, Public Adviser for his useful comments on the review's draft report.

\section{Authors' contributions}

Conceptualisation: Doherty A.J, Clegg A. J, Benedetto V, Harris, C. Data curation: Doherty A. J, Harris C, Benedetto V, Clegg A.J. Formal analysis: Doherty A. J, Benedetto V., Clegg A.J. Writing - original draft: Doherty A. J, Benedetto V., Clegg A.J. Writing - review and editing: Doherty A. J, Benedetto V, Clegg
A. J, Harris C, Boland P, Christian D. L, Hill J, Bhutani G. The author(s) read and approved the final manuscript.

\section{Funding}

The research was funded by the National Institute for Health Research Applied Research Collaboration North West Coast (NIHR ARC NWC). The views expressed are those of the authors and not necessarily those of the NHS, the $\mathrm{NIHR}$, or the Department of Health and Social Care.

Availability of data and materials

All data generated / analysed in this study are included in this published article / supporting files.

\section{Declarations}

Ethical approval and consent to participate

This was a systematic review which did not require specific ethical approval.

\section{Consent for publication}

All the co-authors have provided their consent for publication.

\section{Competing interests}

GB is a co-investigator on a Resilience Hubs evaluation project: NIHR132269 - The Resilience Hubs: A multi-site, mixed-methods evaluation of an NHS Outreach, Screening and Support Navigation service model to address the mental health needs of key workers affected by the COVID-19 pandemic. No competing interests for any of the other co-authors.

\section{Author details}

${ }^{1}$ Synthesis, Economic Evaluations and Decision Science (SEEDS) Group, Faculty of Health \& Care, University of Central Lancashire (UCLan), Preston PR1 2HE, UK. ${ }^{2}$ Lancashire \& South Cumbria NHS Foundation Trust \& University of Liverpool, Liverpool, UK.

Received: 12 March 2021 Accepted: 8 November 2021

Published online: 24 November 2021

\section{References}

1. Aiello A, Khayeri MY, Raja S, Peladeau N, Romano D, Leszcz M, et al. Resilience training for hospital workers in anticipation of an influenza pandemic. J Contin Educ Heal Prof. 2011. https://doi.org/10.1002/chp. 20096.

2. World Health Organisation. Global influenza preparedness plan. Geneva; 2005. https://www.who.int/csr/resources/publications/influenza/WHO_ CDS_CSR_GIP_2005_5.pdf Accessed 15 Apr 2020

3. Canada Public Health Association. Canadian pandemic influenza plan for the health sector. 2006. https://www.longwoods.com/articles/images/ Canada_Pandemic_Influenza.pdf. Accessed 12 June 2020.

4. United States Government. National strategy for pandemic influenza. Washington; 2005. https://www.cdc.gov/flu/pandemic-resources/pdf/ pandemic-influenza-strategy-2005.pdf. Accessed 15 Apr 2020

5. Department of Health UK. UK influenza pandemic contingency plan. 2005. http://news.bbc.co.uk/1/shared/bsp/hi/pdfs/19_10_05_bird_flu. pdf. Accessed 15 Apr 2020.

6. Holmes EA, O'Connor RC, Perry H, Tracey I, Wessley S, Aresenault L, et al. Multidisciplinary research priorities for the Covid-19 pandemic: a call for action for mental health science. Lancet Psychiatry. 2020;7(6):547-60. https://doi.org/10.1016/S2215-0366(20)30168-1.

7. Vindegaard N, Benros ME. COVID-19 pandemic and mental health consequences: systematic review of the current evidence. Brain Behav Immun. 2020. https://doi.org/10.1016/j.bbi.2020.05.048 Published Online First: 2020/06/03.

8. Muller AE, Hafstad EV, Himmels JPW, Smedslund G, Flottorp S, Stensland $\mathrm{SO}$, et al. The mental health impact of the covid-19 pandemic on healthcare workers, and interventions to help them: a rapid systematic review. Psychiatry Res. 2020;293:113441. https://doi.org/10.1016/j.psychres.2020. 113441. 
9. Pappa S, Ntella V, Giannakas T, et al. Prevalence of depression, anxiety, and insomnia among healthcare workers during the COVID-19 pandemic: a systematic review and meta-analysis. Brain Behav Immun. 2020. https:// doi.org/10.1016/j.bbi.2020.05.026.

10. De Kock JH, Latham HA, Leslie SJ, et al. A rapid review of the impact of COVID-19 on the mental health of healthcare workers: implications for supporting psychological well-being. BMC Public Health. 2021;21:104. https://doi.org/10.1186/s12889-020-10070-3.

11. Stuijfzand S, Deforges C, SandozV, et al. Psychological impact of an epidemic/pandemic on the mental health of healthcare professionals: a rapid review. BMC Public Health. 2020;20:1230. https://doi.org/10.1186/ s12889-020-09322-z.

12. Kumar A, Nayar KR. COVID 19 and its mental health consequences. J Ment Health (Abingdon, England). 2020:1-2. https://doi.org/10.1080/09638237. 2020.1757052.

13. Greenberg N, Docherty M, Gananapragasam S, Wessely S. Managing mental health challenges faced by healthcare workers during covid-19 pandemic. BMJ. 2020. https://doi.org/10.1136/bmj.m1211.

14. Maunder R, Hunter J, Vincent L, Bennett J, Peladeau N, Leszcz M, et al. The immediate psychological and occupational impact of the 2003 SARS outbreak in a teaching hospital. CMAJ. 2003;168(10):1245-51.

15. Maunder RG, Leszcz M, Savage D, Adam MA, Peladeau N, Romano D, et al. Applying the lessons of SARS to pandemic influenza: an evidence-based approach to mitigating the stress experienced by healthcare workers. Can J Public Health. 2008;99(6):486-8.

16. Vercio C, Loo LK, Green M, Kim DI, Dallaghan GLB. Shifting focus from burnout and wellness toward individual and organizational resilience. Teach Learn Med. 2021. https://doi.org/10.1080/10401334.2021.1879651.

17. Witteveen AB, Bisson Jl, Ajdukovic D, Arnberg FK, Bergh Johannesson K, Bolding $\mathrm{HB}$, et al. Post-disaster psychosocial services across Europe: the TENTS project. Soc Sci Med. 2012;75(9):1708-14. https://doi.org/10.1186/ 12888-019-2243-z.

18. Te Brake H, Dückers M. Early psychosocial interventions after disasters, terrorism and other shocking events: is there a gap between norms and practice in Europe? Eur J Psychotraumatol. 2013. https://doi.org/10.3402/ ejpt.v4i0.19093.

19. Brooks L. Psychologist tells frontline NHS staff 'it's OK not to be OK': The Guardian; 2020. 25.05.2020. https://www.theguardian.com/world/ 2020/may/25/psychologist-tells-frontline-nhs-staff-its-ok-not-to-be-ok. Accessed 12 June 2020

20. Kenardy J. The current status of psychological debriefing. BMJ (Clinical research ed). 2000;321(7268):1032-3. https://doi.org/10.1136/bmj.321 7268.1032 .

21. Debabeche C, Ansseau M, Pitchot W. Post-traumatic stress disorder and psychological debriefing: a controversial topic. Rev Med Lieg. 2012;67(1):11-5.

22. Magyar J, Theophilos T. Review article: debriefing critical incidents in the emergency department. Emerg Med Australas. 2010;22(6):499-506.

23. National Institute of Health \& Social Care Excellence (NICE). Post-traumatic stress disorder NG1 16. 2018. https://www.nice.org.uk/guidance/ ng116/chapter/Recommendations. Accessed 21 Jul 2020.

24. Zhang J, Wu W, Zhao X, Zhang W. Recommended psychological crisis intervention response to the 2019 novel coronavirus pneumonia outbreak in China: a model of West China hospital. Precis Clin Med. 2020;3(1):3-8. https://doi.org/10.1093/pcmedi/pbaa006.

25. Ahmed MZ, Ahmed O, Aibao Z, Hanbin S, Siyu L, Ahmad A. Epidemic of COVID-19 in China and associated psychological problems. Asian J Psychiatr. 2020;51:102092. https://doi.org/10.1016/j.ajp.2020.102092.

26. Liang L, Ren H, Cao R, Hu Y, Qin Z, Li C, et al. The effect of Covid-19 on youth mental health. Psychiatr Q. 2020;21. https://doi.org/10.1007/ s11126-020-09744-3.

27. Mental Health Today. Coronavirus pandemic disproportionately affecting BAME people - here's how your experiences could inform mental health care responses ... 2020. https://www.mentalhealthtoday.co.uk/news/ inequality/coronavirus-pandemic-disproportionately-affecting-bamepeople-heres-how-your-experiences-could-inform-mental-health-careresponses. Accessed 21 May 2020.

28. Boldt K, Coenen M, Movsisyan A, Voss S, Rehfuess E, Kunzler AM, et al. Interventions to ameliorate the psychosocial effects of the COVID-19 pandemic on children — a systematic review. Int J Environ Res Public Health. 2021;18(5):2361. https://doi.org/10.3390/ijerph18052361.
29. Brooks SK, Dunn R, Amlôt R, Greenberg N, Rubin GJ. Training and postdisaster interventions for the psychological impacts on disaster-exposed employees: a systematic review. J Ment Health. 2018;1-25. https://doi.org/ 10.1080/09638237.2018.1437610.

30. Prieto-Callejero B, Gómez-Salgado J, Alvarado-Gómez F, Dias A, R-F C. Systematic review of the reduction of negative emotional effects in emergency and disaster response workers through catharsis techniques. Arch Prev Riesgos Laborales. 2020;23:52-67. https://doi.org/10.12961/ aprl.2019.22.01.5

31. Ricci Cabello I, Meneses Echavez JF, Serrano-Ripoll MJ, Fraile-Navarro D, Fiol de Roque MA, Pastor Moreno G, et al. Impact of viral epidemic outbreaks on mental health of healthcare workers: a rapid systematic review. medRxiv. 2020:2020.04.02.20048892. https://doi.org/10.1101/2020.04.02. 20048892.

32. Higgins J, Green, S. Cochrane handbook for systematic reviews of interventions UK: Cochrane training; 2019 version 6. 2019. https://training. cochrane.org/handbook. Accessed 12 June 2020.

33. Moher D, Liberati A, Tetzlaff J, Altman DG. Preferred reporting items for systematic reviews and meta-analyses: the PRISMA statement. PLOS Med. 2009. https://doi.org/10.1371/journal.pmed.1000097.

34. Higgins et al., Revised Cochrane risk-of-bias tool for randomized trials (RoB2). Version dated 22.08.2019. https://methods.cochrane.org/bias/ resources/rob-2-revised-cochrane-risk-bias-tool-randomized-trials. Accessed 01 Apr 2021.

35. Al-Alawi M, McCall RK, Sultan A, Al Balushi N, Al-Mahrouqi T, Al Ghailani $A$, et al. Efficacy of a six-week-long therapist-guided online therapy versus self-help internet-based therapy for COVID-19-induced anxiety and depression: open-label, pragmatic, randomized controlled trial. JMIR Ment Health. 2021;8(2):e26683. https://doi.org/10.2196/26683.

36. Carbone GA, Zarfati A, Nicoli MS, Paulis A, Tourjansky G, Valenti G, et al. Online psychological counselling during lockdown reduces anxiety symptoms and negative affect: insights from Italian framework. Clin Psychol Psychother. 2021:1-6. https://doi.org/10.1002/cpp.2608.

37. Dincer $B$, \& Inangil $D$. The effect of emotional freedom techniques on nurses' stress, anxiety, and burnout levels during the COVID-19 pandemic: a randomized controlled trial. Explore (New York, NY) 2021; 17(2): 109114. DOI: https://doi.org/10.1016/j.explore.2020.11.012.

38. Fiol-DeRoque MA, Serrano-Ripoll MJ, Jiménez R, Zamanillo-Campos $R$, Yáñez-Juan AM, Bennasar-Veny M, et al. A Mobile phone-based intervention to reduce mental health problems in health care workers during the COVID-19 pandemic (PsyCovidApp): randomized controlled trial. JMIR Mhealth Uhealth. 2021;9(5):e27039. https://doi.org/10.2196/27039.

39. Gharaati Sotoudeh H, Alavi SS, Akbari Z, Jannatifard F, Artounian V. The effect of brief crisis intervention package on improving quality of life and mental health in patients with COVID-19. Iran J Psychiatry. 2020;15(3):205-12. https://doi.org/10.18502/ijps.v15i3.3812.

40. Xiangyu K, Fanyang K, Kailian Z, Min T, Yi C, Jiahuan Z, et al. Effect of psychological-behavioral intervention on the depression and anxiety of COVID-19 patients. Front Psychiatry. 2020;11:1241. https://doi.org/ 10.3389/fpsyt.2020.586355 https://www.frontiersin.org/article/10.3389/ fpsyt.2020.586355.

41. Jinzhi $L$, Xiuchuan $L$, Jiang Jie $X$, Jing $X W$, Yuanyuan $X$, Xin $L$, et al. The effect of cognitive behavioral therapy on depression, anxiety, and stress in patients with COVID-19: a randomized controlled trial. Front Psychiatry. 2020;11:1096. https://doi.org/10.3389/fpsyt.2020.580827.

42. Liu K, Chen Y, Wu D, Lin R, Wang Z, Pan L. Effects of progressive muscle relaxation on anxiety and sleep quality in patients with COVID-19. Complement Ther Clin Pract. 2020;39:101132. https://doi.org/10.1016/j.ctcp. 2020.101132

43. Liu Y, Yang Y-Q, Liu Y, Pei S-L, Yang H-H, Wu J-J, et al. Effects of group psychological intervention combined with pulmonary rehabilitation exercises on anxiety and sleep disorders in patients with mild coronavirus disease 2019 (COVID-19) infections in a Fangcang hospital. Psychol Health Med. 2021. https://doi.org/10.1080/13548506.2021.1916956.

44. Liu Z, Qiao D, Xu Y, Zhao W, Yang Y, Wen D, et al. The efficacy of computerized cognitive behavioral therapy for depressive and anxiety symptoms in patients with COVID-19: randomized controlled trial. J Med Internet Res. 2021;23(5):e26883. https://doi.org/10.2196/26883.

45. Malboeuf-Hurtubise C, Léger-Goodes T, Mageau GA, et al. Online art therapy in elementary schools during COVID-19: results from a randomized cluster pilot and feasibility study and impact on mental health. 
Child Adolesc Psychiatry Ment Health. 2021;15:15. https://doi.org/10. 1186/s13034-021-00367-5.

46. Ng SM, Chan TH, Chan CL, Lee AM, Yau JK, Chan CH, et al. Group debriefing for people with chronic diseases during the SARS pandemic: strength-focused and meaning-oriented approach for resilience and transformation (SMART). Community Ment Health J. 2006;42(1):53-63. https://doi.org/10.1007/s10597-005-9002-y.

47. Özlü I, Öztürk Z, Karaman Özlü Z, Tekin E, Gür A. The effects of progressive muscle relaxation exercises on the anxiety and sleep quality of patients with COVID-19: a randomized controlled study. Perspect Psychiatr Care. 2021:1-7. https://doi.org/10.1111/ppc.12750.

48. Parizad N, Goli R, Faraji N, Mam-Qaderi M, Mirzaee R, Gharebaghi N, et al. Effect of guided imagery on anxiety, muscle pain, and vital signs in patients with COVID-19: a randomized controlled trial. Complement Ther Clin Pract. 2021;43:101335. https://doi.org/10.1016/j.ctcp.2021.101335. Perri.

49. Perri RL, Castelli P, La Rosa C, Zucchi T, Onofri A. COVID-19, isolation, quarantine: on the efficacy of internet-based eye movement desensitization and reprocessing (EMDR) and cognitive-behavioral therapy (CBT) for ongoing trauma. Brain Sci. 2021;1 1(5):579. https://doi.org/10.3390/brain sci11050579.

50. Procaccia R, Segre G, Tamanza G, Manzoni GM. Benefits of expressive writing on healthcare workers' psychological adjustment during the COVID-19 pandemic. Front Psychol. 2021;12:360. https://doi.org/10.3389/ fpsyg.2021.624176.

51. Shabahang R. Cognitive behavioural intervention for health anxiety, somatosensory amplification, and depression in coronavirus disease 2019 anxiety: an interventional study in Iran. Psychiatr Psychol Klin. 2020;20(2):87-93. https://doi.org/10.15557/PiPK.2020.0011.

52. Thombs BD, et al. Effects of a multi-faceted education and support programme on anxiety symptoms among people with systemic sclerosis and anxiety during COVID-19 (SPIN-CHAT): a two-arm parallel, partially nested, randomised, controlled trial. Lancet Rheumatol. 2021;3(6):e42737. https://doi.org/10.1016/S2665-9913(21)00060-6.

53. Vanden Bossche D, Lagaert S, Willems S, Decat P. Community health workers as a strategy to tackle psychosocial suffering due to physical distancing: a randomized controlled trial. Int J Environ Res Public Health. 2021;18(6):3097. https://doi.org/10.3390/ijerph18063097.

54. Maša VM, Jovana B, Stefan P. Effectiveness of expressive writing in the reduction of psychological distress during the COVID-19 pandemic: a randomized controlled trial. Front Psychol. 2020;11:2936. https://doi.org/ 10.3389/fpsyg.2020.587282
55. Wahlund T, Mataix-Cols D, Olofsdotter Lauri K, de Schipper E, Ljótsson $B$, Aspvall K, et al. Brief online cognitive behavioural intervention for dysfunctional worry related to the COVID-19 pandemic: a randomised controlled trial. Psychother Psychosom. 2021;90:191-9. https://doi.org/10. 1159/000512843.

56. Zheng Y, Wang W, Zhong Y, Wu F, Zhu Z, Tham Y, et al. A peer-to-peer livestreaming intervention for children during COVID-19 homeschooling to promote physical activity and reduce anxiety and eye strain: cluster randomized controlled trial. J Med Internet Res. 2021;23(4):e24316. https://doi. org/10.2196/24316.

57. World Health Organisation. Psychological debriefing in people exposed to a recent traumatic event. 2012. https://www.who.int/mental_health/ mhgap/evidence/other_disorders/q5/en/. Accessed 30 Jul 2020.

58. NHS England, 2020. NHS strengthens mental health support for staff. https://www.england.nhs.uk/2020/10/strengthening-mental-healthsupport-for-staff/. Accessed 28 June 2021.

59. United Nations. Policy Brief: Covid-19 and the need for action on mental health. 2020. https://unsdg.un.org/sites/default/files/2020-05/UN-PolicyBrief-COVID-19-and-mental-health.pdf Accessed 24 Jul 2020.

60. Lake JK, Jachyra P, Volpe T, Lunsky Y, Magnacca C, Marcinkiewicz A, et al. The wellbeing and mental health care experiences of adults with intellectual and developmental disabilities during COVID-19. J Ment Health Res Intellect Disabil. 2021. https://doi.org/10.1080/19315864.2021.18928 90.

61. Graham-Harrison, E., Giuffrida, A., Smith, H., \& Ford, L. (2020, March 28). Lockdowns around the world bring rise in domestic violence. London: The Guardian; https://www.theguardian.com/society/2020/mar/28/lockd owns-world-rise-domestic-violence.

62. Craig P, Dieppe P, Macintyre S, Michie S, Nazareth I, Petticrew M, et al. Developing and evaluating complex interventions: the new Medical Research Council guidance. BMJ. 2008:337:a1655. https://doi.org/10. 1136/bmj.a1655 https://www.bmj.com/content/337/bmj.a1655.

63. O'Cathain A, Croot L, Sworn K, et al. Taxonomy of approaches to developing interventions to improve health: a systematic methods overview. Pilot Feasibility Stud. 2019;5:41. https://doi.org/10.1186/s40814-019-0425-6.

\section{Publisher's Note}

Springer Nature remains neutral with regard to jurisdictional claims in published maps and institutional affiliations.
Ready to submit your research? Choose BMC and benefit from:

- fast, convenient online submission

- thorough peer review by experienced researchers in your field

- rapid publication on acceptance

- support for research data, including large and complex data types

- gold Open Access which fosters wider collaboration and increased citations

- maximum visibility for your research: over $100 \mathrm{M}$ website views per year

At BMC, research is always in progress.

Learn more biomedcentral.com/submissions 